\title{
Effects of sintering temperature and particle size on permeability of functionally gradient composite porous materials prepared by hanging slurry process
}

\author{
Shuai Ji $\mathrm{j}^{1,2,3} \cdot$ Zhongjun Liu $^{1} \cdot$ Gaosong Wang ${ }^{3} \cdot$ Yuan Liu ${ }^{1} \cdot$ Yuan Jing ${ }^{1}$
}

Received: 16 July 2020 / Accepted: 29 October 2020 / Published online: 21 November 2020

(c) Springer Nature Switzerland AG 2020

\begin{abstract}
Porous materials have excellent functions in filtration and purification, and gradient composite porous materials enrich the product types of porous materials in the same field. In the preparation of metal-ceramic gradient composite porous materials, the matching relationship between the pore morphology and pore size of the metal porous matrix and the coated powder particles will seriously affect the structure and performance of the ceramic membrane. This work mentions the different size range $(60,100,200$ and 400 mesh) of $316 \mathrm{~L}$ stainless steel powder particles as the raw materials which are at different sintering temperatures of 1170,1200 and $1230^{\circ} \mathrm{C}$, the fabrication of porous $316 \mathrm{~L}$ stainless steel substrate which was made by hanging slurry preparation of precursor, at the same time using Ar protection at different sintering temperatures $\left(650,700,750\right.$ and $\left.800^{\circ} \mathrm{C}\right)$ to the preparation of metal-ceramic composite gradient according to different matrix apertures of porous materials. The pore structure, microstructure and morphology characteristics of different samples both of matrix and functionally gradient composite were analyzed and characterized. On the basis of test of permeability of functionally gradient composite porous materials, this kind of composite gradient porous material can be excellent at part of permeability which matrix was made by 400 mesh $316 \mathrm{~L}$ stainless steel powder particles at sintering temperature of $1230^{\circ} \mathrm{C}$ and then dealed with the process of hanging slurry to became the precursor which ceramic membrane was prepared at sintering temperature of $650^{\circ} \mathrm{C}$. Maximum aperture of the porous substrate filtration precision under the combination of ceramic membrane layer can be increased by $96.3 \%$. By observing the change of pore morphology of porous matrix, this paper aims to make a research of influence of sintering temperature and powder particles size on permeability of the functionally gradient composite porous materials, and also provide a reference for improving the filtration accuracy of existing porous materials.
\end{abstract}

Keywords $316 \mathrm{~L}$ stainless steel $\cdot$ Hanging slurry process $\cdot \mathrm{TiO}_{2}$ membrane $\cdot$ Functionally gradient composite porous materials · Permeability

\section{Introduction}

Nowadays, as the aggravations of environmental pollution problems and improved shortage of natural resources to become apparent for human beings, we must pay more attention on how to solve the urgent problems which are about recycling of resources, environment protection and effective treatment of industrial waste gas, liquid and solid. A great diversity of porous materials can help us solving these problems as above effectively [1-5]. Especially the

Zhongjun Liu, zjliu@xsyu.edu.cn | ${ }^{1}$ School of Materials Science and Engineering, Xi'an Shiyou University, Xi'an 710065, China. ${ }^{2}$ State Key Laboratory of Materials-Oriented Chemical Engineering, College of Chemical Engineering, Nanjing Tech University, Nanjing 211816, China. ${ }^{3}$ Key Laboratory of Electromagnetic Processing of Materials, Ministry of Education, Northeastern University, Shenyang 110819 , China. 
functionally gradient composite porous materials, which have the characterization of different pore sizes and porosity gradient comparing with the homogeneous porous materials, have become one of hot spots research in recent years according to the weakness of single porous materials [6-9]. By virtue of different structures and functions on those porous materials mentioned earlier, which can ensure the smaller pore size on the basis of a large filtration flux, show greatly improving the filtering accuracy and filtering efficiency in the process of filtration and separation. Functionally gradient composite porous materials with many advantages play a prominent role in this regard, that develop requirements for the porous materials market constantly [10-12]. This is especially true fact in the field of filtration and separation where are many applications. It requires that such materials should have higher filtration accuracy and greater transmittance while having smaller pore size, which makes it difficult for traditional homogeneous porous materials to achieve the desired effect, and the emergence of gradient porous composite materials just solves this contradiction [13-18]. During the process of practical application, in order to guarantee the various properties of porous materials, asymmetric membrane structure is mostly adopted than before. However, pore structure of the matrix will seriously affect the process of film layer formation, which is mainly manifested in that when the pore size of the matrix is large, the fine filmforming particles are easy to enter into the matrix pore with resulting in pore blockage. At the same time, the excessively large matrix aperture makes the film-forming particles prone to collapse on their surface, and it is impossible to form a continuous and effective membrane structure, while the excessively small matrix aperture is difficult to guarantee the requirements of large flux [19-22]. Therefore, the matching degree between the matrix aperture and the film layer particles is an important factor in the membrane coating process. At present, the preparation methods of gradient composite porous materials mainly include 3D printing method, deposition method, sol-gel method, mold pressing method, dealloying method, centrifugal deposition method and bubble template method. Among them above, hanging slurry mode is the most commonly used one and it is easy to achieve in our laboratory. The film layer prepared by this method is uniform, and its thickness is easy to control and the experimental operation is also simple [23-37].

In order to solve the problem of permeability of single metal porous material, we adopt the method of metal foam combined with ceramic coating to prepare functionally gradient composite porous material to change the permeability. The experiment of this work selects hanging slurry method for the preparation of functionally gradient composite porous materials which the matrix is chosen for $316 \mathrm{~L}$ stainless steel powder and ceramic membrane is made by $\mathrm{TiO}_{2}$ powder. Through analyzing the characteristic of the porous membrane pore morphology and composition, characterization of gradient structure and properties, and investigating the influence of different aperture matrix of $\mathrm{TiO}_{2}$ membrane layer, we hope that results of this research can be used for the reference in preparation and performance optimization of functionally gradient composite porous materials, and also provide a referential way to change the permeability of metallic porous materials.

\section{Materials and experiment procedures}

\subsection{Raw material for fabrication of metallic substrate}

By virtue of the stability of $316 \mathrm{~L}$ stainless steel powder under high sintering temperature, we choose $316 \mathrm{~L}$ stainless steel powder which granularity of particles sizes are different as shown in Table 1 as the raw material to prepare the porous substrate by sintering, which chemical elements content is shown in Table 2.

\subsection{Raw material for fabrication of ceramic membrane}

$\mathrm{TiO}_{2}$ powder particle is chosen as the raw material for preparation of $\mathrm{TiO}_{2}$ membrane in this experiment, due to its nice compactness during the process of sintering after made into the membrane layer, which particle size of medium size (D50) is approximate $2.5 \mu \mathrm{m}$.

\subsection{Production of $316 \mathrm{~L}$ stainless steel porous substrate}

Different kinds of $316 \mathrm{~L}$ stainless steel porous substrates were prepared by taking the different particles size into a mould which diameter is $29-30 \mathrm{~mm}$ and its thickness is near 2.4-2.6 mm (ø29-30 × 2.4-2.6 mm). The pressure of $316 \mathrm{~L}$ powder always keeps at $8 \mathrm{MPa}$ when the particle had been put into the mould, at the same time the production process is always under the circular compactness. When preparation of the green billets were finished then they were putted into an atmosphere furnace for sintering process while the protective atmosphere is Argon ( $\mathrm{Ar}$ ). The sintering temperatures are chosen for $1170,1200,1230^{\circ} \mathrm{C}$, respectively. The heating

Table 1 Different powder particle sizes of four kinds of mesh of $316 \mathrm{~L}$ stainless steel (unit: $\mu \mathrm{m}$ )

\begin{tabular}{llllr}
\hline Mesh & 60 & 100 & 200 & 400 \\
Particles size & 250 & 150 & 75 & 38 \\
\hline
\end{tabular}


Table 2 Chemical composition of $316 \mathrm{~L}$ stainless steel powder particle (unit: wt\%)

\begin{tabular}{llllllllllll}
\hline Elements & $\mathrm{Fe}$ & $\mathrm{Cr}$ & $\mathrm{Mn}$ & $\mathrm{Mo}$ & $\mathrm{K}$ & $\mathrm{Ni}$ & $\mathrm{C}$ & $\mathrm{Si}$ & $\mathrm{P}$ & $\mathrm{S}$ \\
Content & 68.752 & 16.394 & 1.493 & 2.075 & 0.021 & 10.336 & 0.077 & 0.528 & 0.025 & 0.007 & Balance \\
\hline
\end{tabular}

rate of sintering process from room temperature is chosen for $5^{\circ} \mathrm{C} / \mathrm{min}$ and the hodling time is $2 \mathrm{~h}$.

\subsection{Manufacture of functionally gradient composite porous materials}

When the porous substrates were prepared with different $316 \mathrm{~L}$ stainless steel powder particles, then the precursors of functionally gradient composite porous materials were fabricated by hanging slurry process. $316 \mathrm{~L}$ stainless steel porous matrix was took into the pulp suspension which was made by $\mathrm{TiO}_{2}$ powder particles adding to the alcohol and stirred thoroughly to obtain a stable suspension mixture with a liquid content of $95 \mathrm{wt} \%$. The $316 \mathrm{~L}$ stainless steel porous matrix was immersed in the mixture repeatedly for half an hour in order to the mixed suspension completely enters the holes of $316 \mathrm{~L}$ porous matrix. After this step has been finished, $316 \mathrm{~L}$ matrix with the suspension mixture was put into a drying oven for an hour which aim is to obtain a membrane with uniform thickness by $\mathrm{TiO}_{2}$ powder particles. Finally, the last step of preparation is to put the precursor fabricated in the previous procedure into the furnace again for sintering. The temperatures of sintering were chosen for $650,700,750,800^{\circ} \mathrm{C}$, respectively, with the holding time of $2 \mathrm{~h}$ and the heating rate was $3^{\circ} \mathrm{C} / \mathrm{min}$ to avoid the problem of micro-cracks according to the speed is too fast.

\subsection{Characterization and performance of functionally gradient composite porous material}

Pore morphology and micro structure of $316 \mathrm{~L}$ stainless steel porous substrates made by different powder particles size and sintering temperature was observed by a scanning electron microscope (SEM) which model type is JSM-6390. The phase transition and composition of the prepared gradient composite porous materials was analyzed by X-ray diffractometer (XRD) which model type is SHIMADZU XRD-6000. A porous material performance detector which was made by ourselves in laboratory was used to characterize the permeability and maximum pore size of this functionally gradient composite porous material. The test principle of the above equipment is based on the bubble method, also known as gas displacement method, which is the most common method for aperture measurement. Saturate the open pores of the sample with a well-wetted liquid, and then slowly push out the liquid immersed in the pores of the sample with a gas. When the gas pressure increases gradually from small to a certain value, the gas can push the impregnated liquid out of the pores and bubble up. According to the pressure difference, the equivalent capillary diameter of the porous sample can be calculated. The first bubble will form in the hole with the largest orifice. The equivalent pore diameter can be calculated according to the pressure at the first bubble point which is the maximum pore diameter of the sample. The resulting aperture value is the throat part of the pore which is the narrowest part of the pore.

\section{Results and discussion}

\subsection{Morphology of structure of $316 \mathrm{~L}$ stainless steel porous materials}

\subsubsection{Sintering temperature at 1170,1200 and $1230^{\circ} \mathrm{C}$}

According to the plan of experiment we designed, four kinds of different sizes of powder particles of $316 \mathrm{~L}$ stainless steel is sintered in a sealed sintering furnace to prepare the porous material which sintering temperature from room temperature to $1170^{\circ} \mathrm{C}$ and the heating rate is $5^{\circ} \mathrm{C} / \mathrm{min}$. Therefore, $316 \mathrm{~L}$ stainless steel porous material can be well manufactured which micro structure and morphology can be clearly shown in Fig. 1. However, the micro morphology of $316 \mathrm{~L}$ stainless steel porous materials is very different, which indicates that the pore size of porous materials and pore morphology have a direct relationship with the size of powder particles at the same sintering temperature of $1170^{\circ} \mathrm{C}$ during the sintering process.

As shown in Fig. 1a, it can be seen that the sintering neck size of porous material is not uniform which was made by $316 \mathrm{~L}$ stainless steel powder particles with 60 mesh $(250 \mu \mathrm{m})$. According to the morphology of different sintered necks of $316 \mathrm{~L}$ porous substrate, it contains both large and small pores. However, it can be clearly observed that the porous material has a good three-connection structure. The uniformity of pore morphology is poor, some pore size is large and some pore size is small, the difference between the twos is very obvious. The reason for the above phenomenon is that the sintering temperature is high that reaches $1170^{\circ} \mathrm{C}$, which provides sufficient driving force for the combination of particles to 

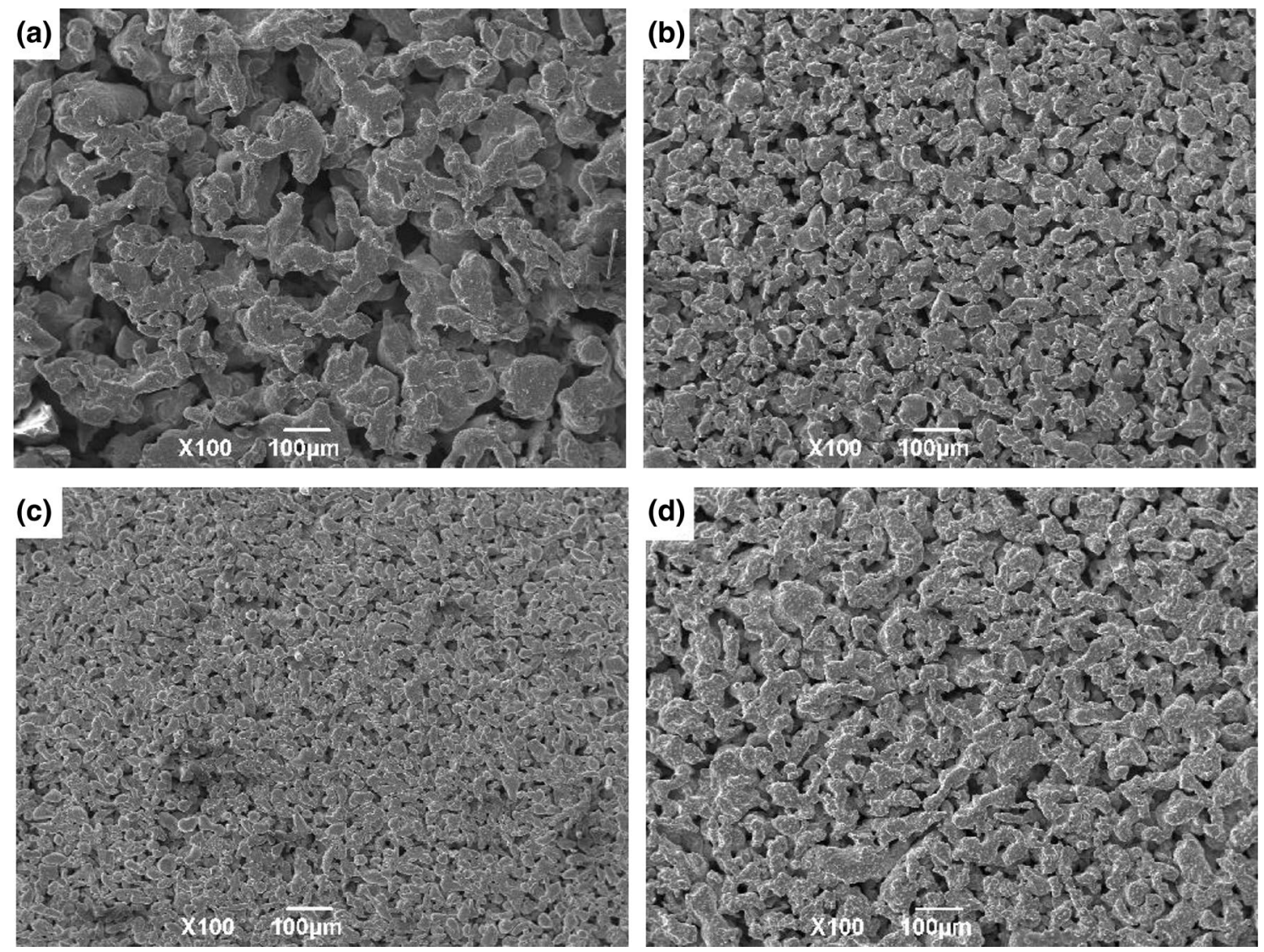

Fig. 1 SEM morphology of porous substrate prepared by $316 \mathrm{~L}$ stainless steel powder of different particles size at sintering temperature of $1170^{\circ} \mathrm{C}$ : (a) 60 mesh; (b) 100 mesh; (c) 400 mesh; (d) 200 mesh

form sintering necks during the sintering process. By virtue of the size of powder particles is larger, it means that the surface area of the particles is also larger, and that induces surface energy of the particles is larger too. As we know that the surface energy is an energy barrier that prevents the particle migrations and bindings, so the larger the surface energy is, the more unfavorable the particle bindings. According to the sintering temperature is constant, the sintering driving force provided for powder particles is consistent. Then, there is a certain difference in particle size of 60 mesh powder particles, which makes the particles with relatively small particle size migrate firstly and combine with surrounding particles with small particle size to produce sintering neck. When the phenomenon of combination arised from two of the smaller particles sintering neck which the whole of surface area is greater than the single particle surface area that there is no migration, so the single particle would precede with sintering neck particle migration and combined with independent particles around a sintering neck in the process of subsequent migration of particles. Because the surface energy differences that leads to small combinations are always there, so that the difference exists in shape between the combinations. And then in the local observations show a clear difference size of hole wall, shape differences apparente and obvious difference both of pore morphology and aperture size, which induces some aperture is greater than $100 \mu \mathrm{m}$ and some aperture is less than $20 \mu \mathrm{m}$.

As shown in Fig. 1b, it can be clearly observed that the uniformity of the porous material prepared by 100 mesh powder particles is significantly improved compared with the one which was made by 60 mesh powder particles. The reason for the above phenomenon is that the particle size of 100 mesh powder particles is $150 \mu \mathrm{m}$ which size is significantly reduced, and the size difference among the particles is also reduced. Therefore, the uniformity of pore size and micro structure of the porous material prepared by sintering process is improved. It can be observed from the same Figure that the size of the hole wall is slightly larger than the size of the hole, the size of the hole is less than $100 \mu \mathrm{m}$ and greater than $30 \mu \mathrm{m}$. The porous material is composed of a large number of triple linkage structures.

The porous material prepared by sintering of 400 mesh $(38 \mu \mathrm{m})$ powder particles is shown in Fig. 1c. Due to the further decrease in the difference of powder particles, it can be seen from the comparison between Fig. $1 \mathrm{c}$ and $\mathrm{b}$

\section{SN Applied Sciences}


that the prepared porous material has higher uniformity and the hole wall size of the porous material is significantly larger than the hole size which is $15-40 \mu \mathrm{m}$. Pore wall size of the porous material prepared by $\mathbf{4 0 0}$ mesh powder is significantly smaller than shown in Fig. $1 \mathrm{a}$ and Fig. $1 \mathrm{~b}$, which fully indicates that the powder particle size directly determines the micro structure and micro morphology of $316 \mathrm{~L}$ porous substrate.

Figure $1 \mathrm{~d}$ is the micro structure and morphology of porous materials prepared by 200 mesh $(75 \mu \mathrm{m})$ powder particles sintering. According to the analysis above we know that the aperture size shown in Fig. $1 \mathrm{~d}$ shall be less than the aperture size shown in Fig. $1 \mathrm{~b}$ and greater than that shown in Fig. 1c. By magnifying five times on the original basis, it can be seen that the pore size of the same porous material varies greatly. The reason for the above phenomenon is that the size of powder particles is different and the surface energy is obviously different. As a result, the state difference under the driving force of sintering is obvious, which then manifests in the micro structure of porous materials.

It can be seen from four diagrams of Fig. 1 that the hole wall is not straight and the morphology of the hole wall is not uniform. This indicates that when the sintering temperature provides driving force during the sintering process, the powder particles migrate in accordance with the order of energy barrier resistance and combine with the particles with the smallest difference in energy on the surrounding surface to form sintering neck, which just shows the result of random combination at the same energy level in the sintering process. It also shows that the whole sintering process can be composed of many divided energy level changes.

The micro-structure of porous materials prepared by sintering four different powder particles of $316 \mathrm{~L}$ stainless steel at sintering temperature of 1200 and $1230^{\circ} \mathrm{C}$ looed the same like the showings in Fig. 1. At the same sintering temperature, the microstructure of porous materials prepared with different particle sizes was different obviously. The comparison with Fig. 1 shows that the change of powder particles of the same size after the sintering temperature increases by 30 and $60^{\circ} \mathrm{C}$ is not obvious. It indicates that when the sintering temperature can provide sufficient driving force for sintering process, the particle size of the powder does not change, and then the micro structure and micro morphology of the prepared porous materials basically do not change. The sintering temperature is so high that can change the bonding rate between powder particles which could improve the overall sintering efficiency of powder particles, but not change the micro structure and micro morphology of porous materials.

According to the SEM pictures, by comparing the same size of powder particle at different sintering temperature of 1170,1200 and $1230^{\circ} \mathrm{C}$, it can be seen that the sintering temperature of $1170-1230^{\circ} \mathrm{C}$ enables powder particles with different particle sizes to be sintered into porous materials. Under the premise of constant temperature, the pore size and pore morphology of porous materials are closely related to the size of powder particles. The larger the particle size of the powder is, the larger the pore size of the porous material is, but the pore morphology is also very different, and the pore size uniformity is poor. The smaller the particle size of the powder particle, the more uniform the pore size distribution of the porous material, the smaller the pore size, the pore morphology difference is very small. But the pore size and pore wall size are significantly different. Under the premise that the sintering temperature is sufficient to provide sintering driving force, the higher the temperature is, the worse the hole wall smoothness of the porous material will be. This indicates that the higher the sintering temperature is, the better the holding time can be, so that the sintering preparation technology becomes more reasonable.

\subsubsection{Permeability and max pore of $316 \mathrm{~L}$ stainless steel porous substrate}

Permeability is the flow rate of gas through a porous material per unit area under unit pressure difference. The measurement of breathability is equivalent to the dry film differential pressure flow measurement in the bubble pressure method [29-32]. It can be seen from the above that the pore size, pore morphology, permeability and other aspects of $316 \mathrm{~L}$ stainless steel porous materials are closely related to the particle size of powder particles at the same sintering temperature. The permeability coefficient and maximum pore diameter of the porous materials prepared by four kinds of different powder particle sizes at three different sintering temperatures are shown in Table 3.

Permeability refers to the gas flow rate through the porous material per unit area under the unit pressure difference. The measurement of permeability is equivalent to that of the dry film pressure differential flow method. It can be calculated according to Eq. (1):

$I=U / \Delta P$

where, $I$ is the permeability, and the unit is $\mathrm{m}^{3} \mathrm{~h}^{-1} \mathrm{~m}^{-2} . U$ is the gas flow rate, and the unit is $\mathrm{m}^{3} \mathrm{~h}^{-1} ; \Delta P$ is the differential pressure of the gas through the porous body, and the unit is $\mathrm{KPa}$.

The maximum pore size of gradient porous material was measured by bubble pressure method. Alcohol of $95 \mathrm{wt} \%$ was selected as the test medium. After the sample was fully soaked, $\mathrm{N}_{2}$ was used to gradually expel the alcohol from the pores of the porous substance. In the process 
Table 3 Permeability coefficient and max pore size of $316 \mathrm{~L}$ stainless steel matrix made in different sintering temperature and powder particles

\begin{tabular}{|c|c|c|c|c|c|c|}
\hline \multirow{3}{*}{$\begin{array}{l}\text { Different particles } \\
\text { size of matrix } \\
\text { powder }\end{array}$} & \multicolumn{6}{|c|}{ Different sintering temperature of preparation of $316 \mathrm{~L}$ stainless steel porous substrates } \\
\hline & \multicolumn{2}{|l|}{$1170^{\circ} \mathrm{C}$} & \multicolumn{2}{|l|}{$1200^{\circ} \mathrm{C}$} & \multicolumn{2}{|l|}{$1230^{\circ} \mathrm{C}$} \\
\hline & $\begin{array}{l}\text { Permeability coef- } \\
\text { ficient of matrix } \\
\left(\mathrm{m}^{3} \mathrm{~h}^{-1} \mathrm{~m}^{-2}\right)\end{array}$ & $\begin{array}{l}\text { Max pore size } \\
\text { of matrix }(\mu \mathrm{m})\end{array}$ & $\begin{array}{l}\text { Permeability coef- } \\
\text { ficient of matrix } \\
\left(\mathrm{m}^{3} \mathrm{~h}^{-1} \mathrm{~m}^{-2}\right)\end{array}$ & $\begin{array}{l}\text { Max pore size } \\
\text { of matrix }(\mu \mathrm{m})\end{array}$ & $\begin{array}{l}\text { Permeability coef- } \\
\text { ficient of matrix } \\
\left(\mathrm{m}^{3} \mathrm{~h}^{-1} \mathrm{~m}^{-2}\right)\end{array}$ & $\begin{array}{l}\text { Max pore size } \\
\text { of matrix }(\mu \mathrm{m})\end{array}$ \\
\hline $60 \mathrm{mesh} / 250 \mu \mathrm{m}$ & 430 & 161 & 431 & 172 & 428 & 155 \\
\hline $100 \mathrm{mesh} / 150 \mu \mathrm{m}$ & 243 & 94 & 247 & 97 & 238 & 91 \\
\hline $200 \mathrm{mesh} / 75 \mu \mathrm{m}$ & 116 & 78 & 120 & 79 & 115 & 74 \\
\hline $400 \mathrm{mesh} / 38 \mu \mathrm{m}$ & 71 & 19 & 73 & 20 & 70 & 17 \\
\hline
\end{tabular}

of gas pressure from small to large, bubbles will be generated. The corresponding pressure value when the first bubble appears is recorded, and the maximum bubble aperture $D$ of the material is calculated according to the formula:

$D=4 T \cos \theta / \Delta P$

where, $T$ is the surface tension of liquid, unit in $\mathrm{N} / \mathrm{m}^{-1}$, and the alcohol surface tension is $T \approx 22.3 \times 10^{3} \mathrm{~N} / \mathrm{m}^{-1}$. $\theta$ is the contact angle of liquid medium to porous material; $\Delta P$ is the pressure difference acting on the sample. Since $95 \mathrm{wt} \%$ of alcohol has good wettability to stainless steel materials, $\theta$ can be approximately zero, and then Eq. (2) can be simplified as followed:

$D=4 T / \Delta P$

Table 3 shows the pressure difference corresponding to the maximum bubble aperture of the porous matrix and the gradient porous material. The maximum pore diameter of the sample material can be calculated by Eq. (3), and the calculation results are also shown in Table 3.

It can be seen from Table 3 that, on the premise of the same powder particle size, the change of sintering temperature has little influence on the permeability coefficient and maximum pore diameter of porous materials. The reasons have been explained before. However, too high sintering temperature is also unfavorable for the preparation of porous materials, which may cause excessive sintering between powders, reduce the size of pore diameter and increase the thickness of pore wall. Therefore, the matching of sintering temperature and holding time is very important for optimizing sintering process.

Under the premise of the same sintering temperature, the particle size of powder directly affects the pore size and pore structure of porous materials. This also directly affects the change of permeability coefficient as shown in Fig. 2. The larger the particle size of the powder, the larger the pore size of the prepared porous material, the larger the permeability coefficient, but the smaller the filtration accuracy. The smaller the particle size of the powder, the smaller the pore size of the prepared porous material, the smaller the permeability coefficient, but the filtration accuracy becomes greater than before. But this is not a linear relationship between the powder particles size and the ability of $316 \mathrm{~L}$ porous materials. It can be observed from Table 3 that the permeability coefficient and the maximum pore size of the porous materials prepared under the preparation process of sintering temperature of $1200^{\circ} \mathrm{C}$ for $2 \mathrm{~h}$ were the best.

\subsection{Structure of functionally gradient composite porous materials}

\subsubsection{Morphology of functionally gradient composite porous materials}

The SEM images of the micro structure and micro morphology of $\mathrm{TiO}_{2}$ ceramic membrane and $316 \mathrm{~L}$ porous matrix

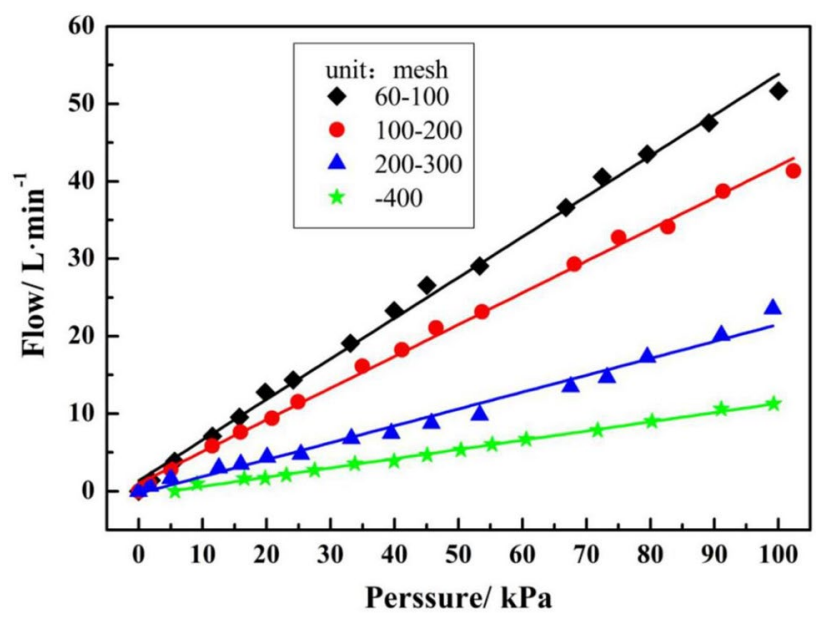

Fig. 2 Permeability of porous matrix prepared by $316 \mathrm{~L}$ stainless steel powder of four kinds of different mesh at sintering temperature of $1200^{\circ} \mathrm{C}$ 
are shown in Fig. 3. It can be clearly seen from Fig. 3a that the $\mathrm{TiO}_{2}$ membrane of porous substrate prepared by $316 \mathrm{~L}$ stainless steel powder particles for 60 mesh is about $100 \mu \mathrm{m}$ thickness, and the $\mathrm{TiO}_{2}$ ceramic membrane covers the pore plane of the porous substrate. As can be seen from the picture, there are no large holes along the thickness of $\mathrm{TiO}_{2}$ ceramic membrane. This indicates that the binding between $\mathrm{TiO}_{2}$ powder particles and the matrix is very close. The powder is well filled into the matrix hole, and a dense film layer is formed and reaches a certain depth in the hole. However, the large holes outside the $\mathrm{TiO}_{2}$ membrane in the matrix are still clearly visible. This does not change the flux of substrate much, but improves the filtration accuracy of substrate obviously. It can be clearly seen from Fig. 3b that, compared with Fig. 3a, the thickness of $\mathrm{TiO}_{2}$ ceramic membrane with porous substrate prepared by 100 mesh $316 \mathrm{~L}$ stainless steel powder particles is somewhat smaller, about $50-70 \mu \mathrm{m}$. The reason of $\mathrm{TiO}_{2}$ membrane thinning is mainly related to the pore size of the matrix. Compared with 60 mesh powders, the size of powder particles and the size of matrix aperture of 100 mesh powder are smaller, the smoothness of pore wall is improved, and the friction coefficient is reduced. As a result, the amount of $\mathrm{TiO}_{2}$ particles entering the pore reaches saturation state under the action of adsorption force is small, that induce the $\mathrm{TiO}_{2}$ membrane thickness thus formed decreases. Although the thickness of the membrane decreases, the filtration accuracy of the film layer does not change so much. Because the film thickness is relatively thin, the film improves the overall filtration accuracy and does not affect the matrix flux too much. As can be clearly seen from Fig. 3c, compared with Fig. 3a, $b$, the ceramic layer thickness of functionally gradient composite porous materials is significantly thinner, with a thickness less than $50 \mu \mathrm{m}$. The pore size of alloy matrix decreases obviously, but the uniformity of pore size of alloy matrix increases. Due to the decrease of size of the pore diameter of the stainless steel matrix and the friction coefficient of the pore wall, and the relatively small absorption force of the pore of the matrix for $\mathrm{TiO}_{2}$ mixed solution, the number of $\mathrm{TiO}_{2}$ powder particles entering the pore of the matrix is limited. Therefore, the $\mathrm{TiO}_{2}$ membrane prepared after subsequent sintering is relatively thin. At the same time, due to the relatively small adsorption capacity
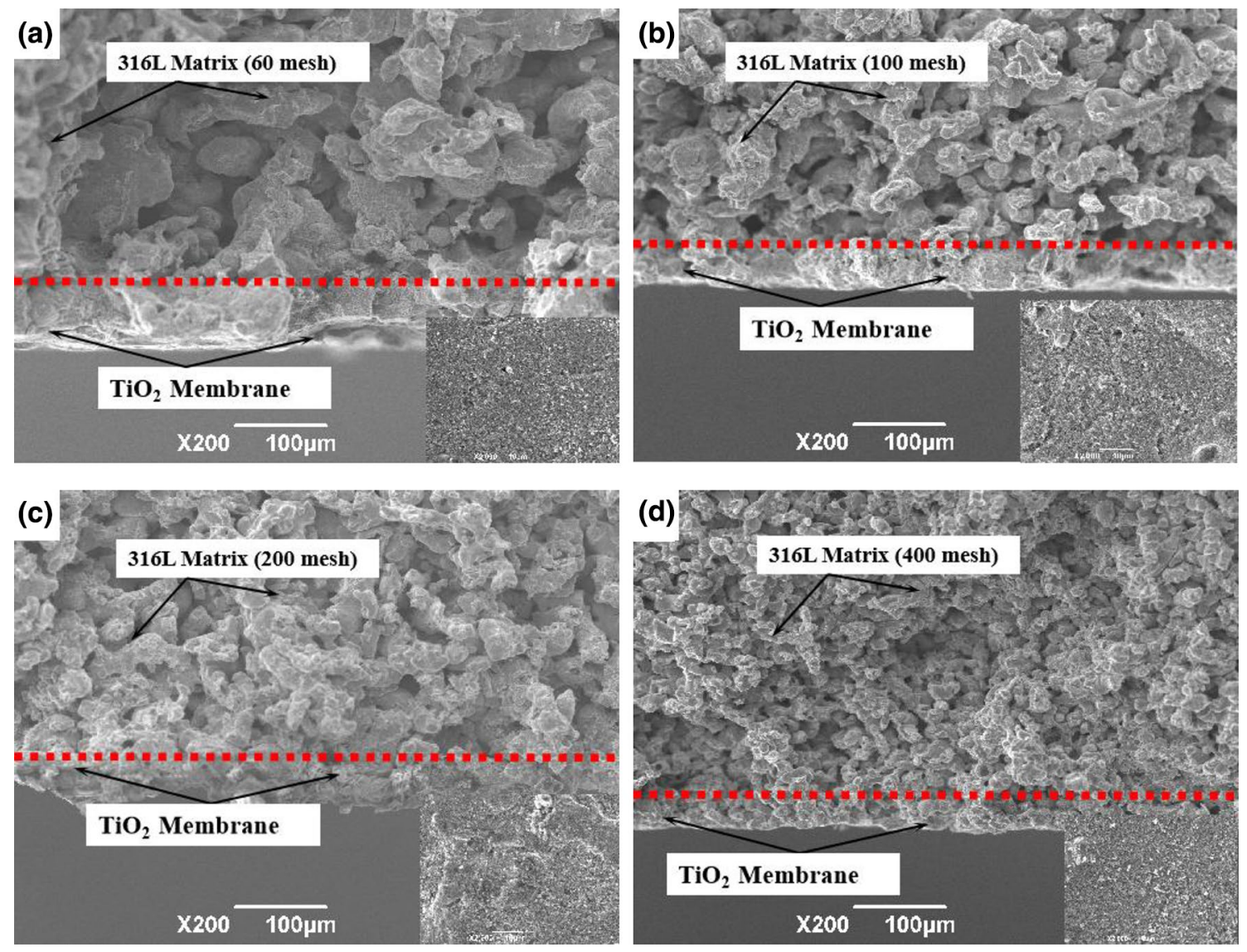

Fig. 3 Micro-structure of gradient porous composite material and relationship between $\mathrm{TiO}_{2}$ membrane and different $316 \mathrm{~L}$ stainless steel substrates: (a) 60 mesh; (b) 100 mesh; (c) 200 mesh; (d) 400 mesh 
of alloy matrix pores on molten liquid, a small amount of $\mathrm{TiO}_{2}$ powder particles did not enter into the depth of the pores, so $\mathrm{TiO}_{2}$ ceramic membrane would not have too much influence on the pass rate while improving the filtration accuracy of matrix. By comparing the first three diagrams, the $\mathrm{TiO}_{2}$ membrane shown in Fig. $3 \mathrm{~d}$ has the thinest thickness, about $20-30 \mu \mathrm{m}$. The causes are similar to those in the previous three pictures. As the alloy matrix is prepared by sintering 400 mesh powders, the pore diameter of the alloy matrix and the friction coefficient of the pore wall are the smallest, so the adsorbability of the matrix to the liquid is relatively small. Under the action of adsorption force, there is little molten liquid entering the hole, and the amount of $\mathrm{TiO}_{2}$ powder particles is also small, leading to the thinnest $\mathrm{TiO}_{2}$ membrane prepared after subsequent sintering. It can be clearly observed from the figure that $\mathrm{TiO}_{2}$ powder particles do not enter the depth of the pores of the matrix, which will not affect the flux of the matrix, but the filtration accuracy will be significantly improved on the side with $\mathrm{TiO} 2$ ceramic membrane.

Through the comparison of the four images in Fig. 3, it can be observed that after the formation of $\mathrm{TiO}_{2}$ membrane, and it is difficult to observe the differences between different substrates in the preparation of functionally gradient porous composite materials from the front of the film layer, and the front of $\mathrm{TiO}_{2}$ ceramic membrane is consistent. However, when observed from the side of functionally gradient composite porous material that is cut along the thickness direction, the morphologies presented in the four pictures are very different, but they also show some commonness. The functionally gradient composite porous material has similar structure, and $\mathrm{TiO}_{2}$ membrane has the same structure and morphology.

\subsubsection{Relationship between $\mathrm{TiO} 2$ membrane and $316 \mathrm{~L}$ stainless steel matrix}

The $316 \mathrm{~L}$ stainless steel porous materials sintered with different powder particle sizes were treated with hanging slurry process, so as to observe the influence of the pore morphology and pore size of the porous matrix on the $\mathrm{TiO}_{2}$ membrane by the same pulping process. The precursor is prepared by hanging slurry method and sintering process. The relationship between the ceramic membrane and the metallic matrix is shown in Fig. 4 which is a schematic diagram of $\mathrm{TiO}_{2}$ particles and $316 \mathrm{~L}$ stainless steel porous matrix after hanging slurry procedure. The pore size of $316 \mathrm{~L}$ stainless steel porous matrix, the pore size and the friction degree of the pore wall have obvious influences on $\mathrm{TiO}_{2}$ powder particles during the slurry hanging process. This makes the appearance and thickness of $\mathrm{TiO}_{2}$ membrane have great differences. The reason is that there is a significant difference in the adsorption of $\mathrm{TiO}_{2}$ alcohol

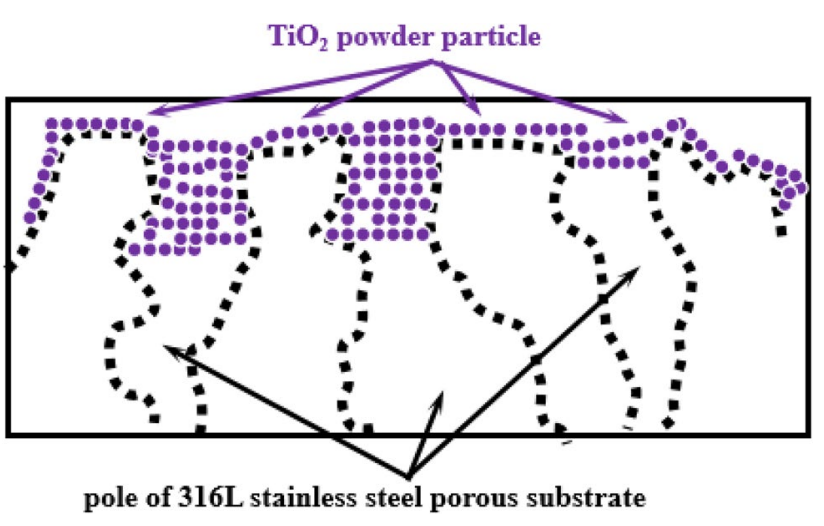

Fig. 4 Sketch of micro-structure of gradient composite porous made by hanging slurry process

solution. The pore structure with large pore size, deep pore and thick pore wall has a large adsorption capacity on $\mathrm{TiO}_{2}$ alcohol solution, leading to more $\mathrm{TiO}_{2}$ particle solution entering the pore. In addition, the greater friction of the pore wall makes more $\mathrm{TiO}_{2}$ particles accumulate in the pore. In the subsequent sintering process, $\mathrm{TiO}_{2}$ powder particles prepared ceramic membrane layer thickness is relatively large. Some matrix pore structures with small pore size, thin and relatively smooth pore wall and shallow pore have relatively small amount of $\mathrm{TiO}_{2}$ particle solution entering the pore and relatively small thickness of $\mathrm{TiO}_{2}$ ceramic layer prepared after sintering. Therefore, it is very different for the transmittance of functionally gradient composite porous materials prepared by both hanging slurry method and sintering process.

Figure 5 is the schematic diagram base on a further analysis of Fig. 4. The method of hanging slurry is to soak $316 \mathrm{~L}$ stainless steel porous matrix with different pore diameters into $\mathrm{TiO}_{2}$ particle solution, and then the precursor was fabricated. Finally, the precursor is sintered to prepare the functionally gradient composite porous material. The process steps are not complicated, but the $\mathrm{TiO}_{2}$ ceramic layer prepared varies greatly in the slurry process due to the difference in the pore size of the alloy matrix. The main reason of phenomenon above is the variety of matching relationships between $\mathrm{TiO}_{2}$ particles and the matrix. The specific reason is that the pore size of the matrix, the thickness of the pore wall, the depth of the pore wall and the friction of the pore wall are very different. Due to the small size of $\mathrm{TiO}_{2}$ particles, the effect of the substrate on $\mathrm{TiO}_{2}$ particles in the solution state is significantly affected by its own state details. The porous matrix prepared by $316 \mathrm{~L}$ powder particles with large powder particles has a large amount of $\mathrm{TiO}_{2}$ particle solution entering under the action of large adsorption force by virtue of its large pore diameter, thick pore wall, deep pore wall and large friction on the pore wall. $\mathrm{TiO}_{2}$ particles will 

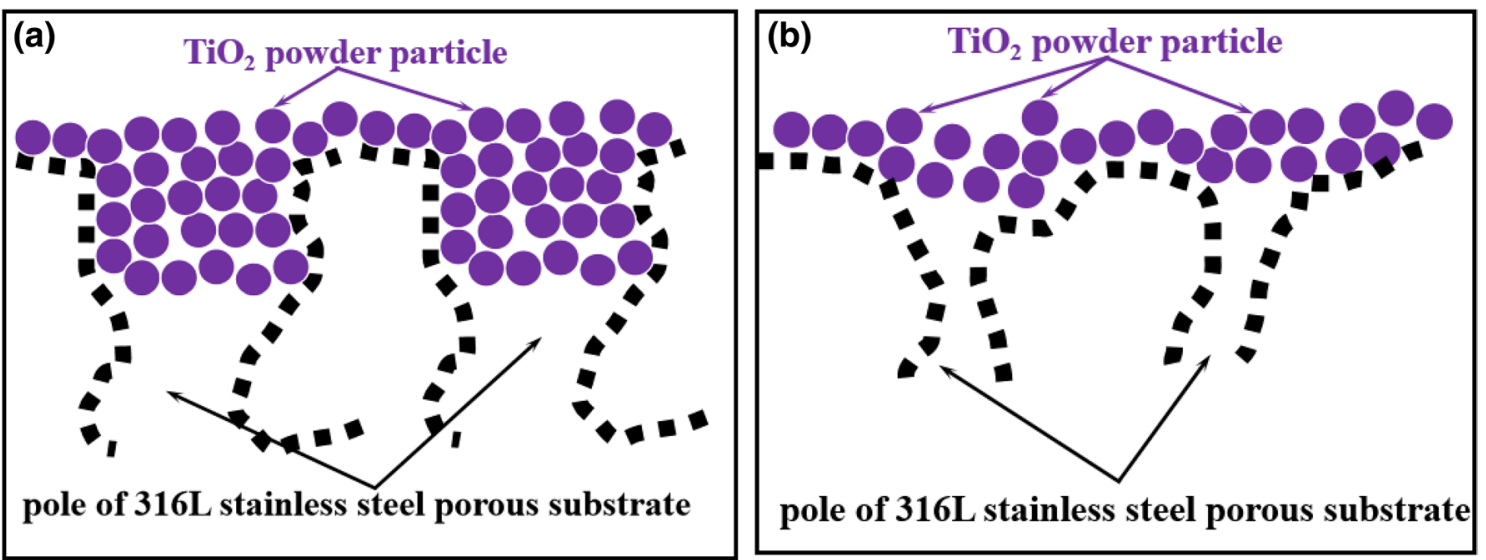

Fig. 5 Sketch of micro-structure of gradient composite porous materials made by hanging slurry process: (a) 60 mesh; (b) 400 mesh

be adsorbed on the pore wall after contacting with the pore wall of the matrix hole. Due to the relatively large contact area of the pore wall, a large number of $\mathrm{TiO}_{2}$ particles will be absorbed. As a result, the amount of $\mathrm{TiO}_{2}$ particles in this area is relatively large, and the subsequent $\mathrm{TiO}_{2}$ ceramic layer prepared through sintering is relatively large too. In the sintering process, due to the combination between too many $\mathrm{TiO}_{2}$ particles, the interaction between $\mathrm{TiO}_{2}$ particles in the pore was strong. As a result, the $\mathrm{TiO}_{2}$ membrane at the pore is collapsed in a certain, which will accumulate more $\mathrm{TiO}_{2}$ particles, making the ceramic membrane slightly higher than the plane where the pore is located. $\mathrm{TiO}_{2}$ ceramic layer has a high bonding strength with the matrix, which results in a decrease in the transmittance of the obtained porous functionally gradient composite porous materials, but it is an increase in the filtration accuracy as shown in Fig. 5a. The porous matrix prepared by $316 \mathrm{~L}$ powder particles with small powder particles has a small amount of $\mathrm{TiO}_{2}$ particle solution entering under the action of small adsorption force due to small pore size, thin pore wall, shallow pore wall and small friction of pore wall. $\mathrm{TiO}_{2}$ particles will be adsorbed on the pore wall after contacting with the pore wall of the matrix hole. However, the adsorption is weak. According to the small contact area of the pore wall, the absorbed amount of $\mathrm{TiO}_{2}$ particles is also small. As a result, the amount of $\mathrm{TiO}_{2}$ particles in this area is also small, which makes the subsequent $\mathrm{TiO}_{2}$ ceramic layer prepared by sintering thinner. In the sintering process, due to the binding between a small amount of $\mathrm{TiO}_{2}$ particles, the interaction between the $\mathrm{TiO}_{2}$ particles in the pore and the $\mathrm{TiO}_{2}$ particles outside the pore mouth was not strong after the interaction. Therefore, $\mathrm{TiO}_{2}$ membrane at the pore has insufficient binding strength with the matrix, making the membrane easy to fall off. Thus, the membrane appears to be concave in morphology, which appears to be slightly lower than the plane where the orifice is located. The bonding strength of $\mathrm{TiO}_{2}$ membrane and matrix is relatively small, and the thickness of the film is also small, which will not seriously affect the transmittance of ceramic porous composites while improving the filtration accuracy of alloy matrix as shown in Fig. 5b. Due to the large difference in pore size and morphology of the porous matrix of $316 \mathrm{~L}$ stainless steel prepared, the thickness of $\mathrm{TiO}_{2}$ ceramic membrane prepared after hanging slurry process and its bonding strength with the matrix also differ greatly. But what happens is within the scope of the diagrams in Fig. 5a, b.

\subsection{Analysis of XRD of $\mathrm{TiO}_{2}$ membrane}

The sintering temperature is one of the important factors affecting the performance of the $\mathrm{TiO}_{2}$ membrane. Different temperatures are selected for sintering after hanging slurry process on the same substrate, and the different sintered $\mathrm{TiO}_{2}$ film layers are analyzed by XRD. As showing in Fig. 6, we can see the XRD patterns of the membrane of four samples sintered at different temperatures during $650-800^{\circ} \mathrm{C}$. It can be seen from the Fig. 6 that when the sintering temperature is $650^{\circ} \mathrm{C}$, the $\mathrm{TiO}_{2}$ membrane is dominated more by structure of Anatase and also contains a small amount of Rutile structure. When the sintering temperature was elevated to $700{ }^{\circ} \mathrm{C}$, the Anatase characteristic peak of $\mathrm{TiO}_{2}$ membrane did not change, and the Rutile characteristic peak still existed, which indicated that the structure of $\mathrm{TiO}_{2}$ membrane was relatively stable within the sintering temperature range of $650-700{ }^{\circ} \mathrm{C}$. When the temperature developed with the same scope like before at $750^{\circ} \mathrm{C}$, the characteristic peak of structure of $\mathrm{TiO}_{2}$ membrane as the same as the sample at $700^{\circ} \mathrm{C}$. The phenomenon illustrates that structure of $\mathrm{TiO}_{2}$ membrane is steady within the temperature range of $650-750{ }^{\circ} \mathrm{C}$, always keep the structure more Anatase and less Rutile. 


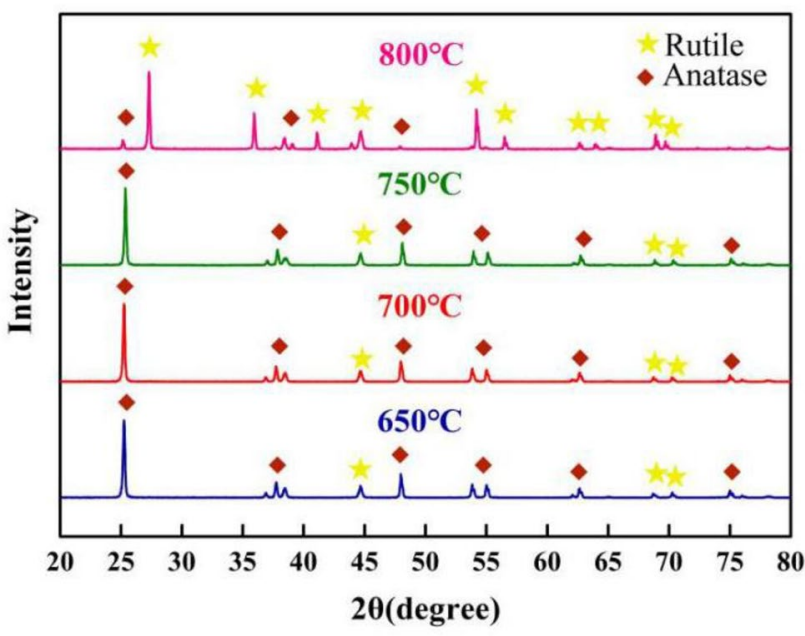

Fig. 6 XRD patterns of $\mathrm{TiO}_{2}$ membrane sintered at different temperature according to the same porous substrates of 100 mesh at sintering temperature of $1200^{\circ} \mathrm{C}$

As the temperature continues to rise to $800^{\circ} \mathrm{C}$, the Anatase type of $\mathrm{TiO}_{2}$ membrane characteristic peaks most disappear, but appear a large number of Rutile type characteristic peaks at the same time. The description like above reveal that the sintering temperature is one of important influence factors of $\mathrm{TiO}_{2}$ structure transformation. It is well known that high sintering temperature offers high chemical driving force, the increase of temperature from 750 to $800^{\circ} \mathrm{C}$ affords the driving force to transform type structure of Anatase to Rutile. The experimental results showed that $\mathrm{TiO}_{2}$ structure transition zone existed between 750 and $800^{\circ} \mathrm{C}$. When the sintering temperature was higher than $800^{\circ} \mathrm{C}$, most type structure of Anatase was transformed into Rutile.

Figure 7 is the XRD pattern of the sample film of ceram porous material sintered at four different temperatures by the precursor prepared by substrates with different pore sizes. As can be seen from the figure, during the sintering process, the characteristic peak of $\mathrm{TiO}_{2}$ shifted slightly with the change of the pore size of the matrix. Since XRD is to show the relationship between crystal plane and reflection angle, the shift of XRD peak can only be related to the change of lattice index. The deviation of the characteristic peak in this experiment may be caused by the height deviation of the sample during the test. Through further analysis by XRD, it can be seen that the main factor affecting $\mathrm{TiO}_{2}$ is sintering temperature, which is basically independent of the pore morphology of the matrix. The slight shift of the characteristic peak does not affect the performance of the membrane, so the porous matrix has no obvious influence on the sintering of $\mathrm{TiO}_{2}$ membrane.

It can be observed from Fig. 7 a that $316 \mathrm{~L}$ porous stainless steel substrates prepared by four kinds of different size of powders were sintered at $800{ }^{\circ} \mathrm{C}$ after hanging slurry process. Then the membrane of $\mathrm{TiO}_{2}$ was analyzed by XRD. It was found that the phase of $\mathrm{TiO}_{2}$ on the substrate with four different pore sizes was consistent, which are composed of a large number of Rutile structures and a small amount of Anatase structures. This indicates that the phase composition of $\mathrm{TiO}_{2}$ is determined by the sintering temperature and has no relationship with the pore size and pore morphology of the matrix. As we know that the binding conditions between different amounts of $\mathrm{TiO}_{2}$ powder particles gathered in different pore diameters are the same, but the amount of $\mathrm{TiO}_{2}$ leads to the difference in the thickness of $\mathrm{TiO}_{2}$ membrane.

It can be observed from Fig. $7 \mathrm{~b}$ that $316 \mathrm{~L}$ porous stainless steel matrix prepared by four powders with different particle sizes was in hanging slurry process and sintered at $750^{\circ} \mathrm{C}$. Compared with Fig. $7 \mathrm{a}$, other conditions are the same, but the sintering temperature is $50^{\circ} \mathrm{C}$ lower. According to XRD phase analysis, the phase of $\mathrm{TiO}_{2}$ ceramic layer changes significantly. In this film, the phase proportion of the striated mineral structure increased significantly, which indicated that for $\mathrm{TiO}_{2}$ membrane, the sintering temperature was between 750 and $800^{\circ} \mathrm{C}$, and there was a phase transition temperature, resulting in the transformation of the striated mineral structure into the rutile structure. $\mathrm{TiO}_{2}$ membrane was prepared by sintering $316 \mathrm{~L}$ stainless steel matrix with four different powder particle sizes after slurry hanging process. It can be seen from the figure that at the same sintering temperature of $750{ }^{\circ} \mathrm{C}$, the pore morphology and pore size of the matrix have no influence on the phase composition of $\mathrm{TiO}_{2}$ membrane. The phase composition of the film layer is determined by the sintering temperature on the premise that $\mathrm{TiO}_{2}$ powder particle size is the same. Therefore, $\mathrm{TiO}_{2}$ membrane on different substrates has the same phase composition at the same sintering temperature of $750^{\circ} \mathrm{C}$. Similar conclusions can be observed in Figs. 7c, d, which are XRD phase analysis of $\mathrm{TiO}_{2}$ membrane at sintering temperature of $700{ }^{\circ} \mathrm{C}$ and $650^{\circ} \mathrm{C}$ respectively. It can be clearly observed from these two figures that the phase composition of the two objects at different sintering temperatures is similar, both are the structure of a large number of Anatase and the structure of a small number of Rutile. Moreover, they are similar to Fig. $7 \mathrm{~b}$, which indicates that within the sintering temperature range of $650-750^{\circ} \mathrm{C}$, the phase composition of $\mathrm{TiO}_{2}$ membrane prepared is very stable and will not change with the increase of sintering temperature. At the same time, the phase of $\mathrm{TiO}_{2}$ membrane is not affected by the pore size and morphology of the matrix.

In conclusion, through the comparative analysis in Fig. 7, it can be seen that there are mainly two kinds of phase structures in $\mathrm{TiO}_{2}$ membrane. In a lower temperature range of $650-750^{\circ} \mathrm{C}$ sintering temperature, more 

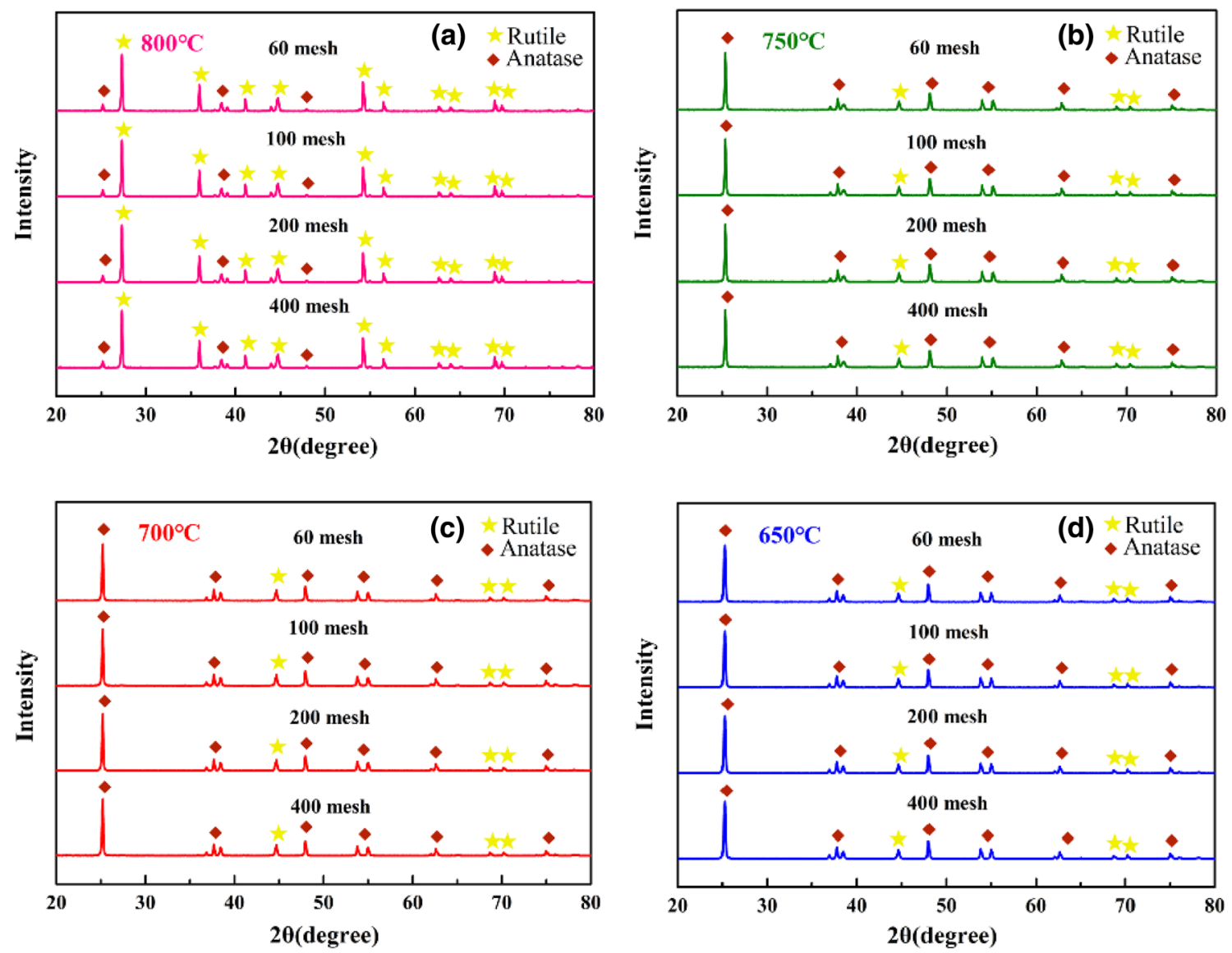

Fig. 7 XRD patterns of $\mathrm{TiO}_{2}$ membrane sintered at different temperature according to the different porous substrates of different mesh at sintering temperature of $1200^{\circ} \mathrm{C}$ : (a) $800^{\circ} \mathrm{C}$; (b) $750^{\circ} \mathrm{C}$; (c) $700^{\circ} \mathrm{C}$; (d) $650^{\circ} \mathrm{C}$

phases are striated ore structure. When the sintering temperature rises to $800^{\circ} \mathrm{C}, \mathrm{TiO}_{2}$ phase is more rutile structure. Moreover, a certain temperature between 750 and $800^{\circ} \mathrm{C}$ is the transition temperature from Anatase to Rutile.

\subsection{Morphology of $\mathrm{TiO}_{2}$ membrane coating on the $316 \mathrm{~L}$ substrate}

According to the previous studies, for the porous matrix of $316 \mathrm{~L}$ stainless steel, on the premise that the sintering temperature difference is not very obvious, the structural difference of the pore size and pore morphology of the matrix mainly depends on the particle size of $316 \mathrm{~L}$ powder particles. It can be observed from previous experiments that the larger the particle size of the powder is, the larger the pore size of the porous matrix is, and the smaller the particle size is, the smaller the pore size of the porous matrix is. Therefore, the study on the preparation of $\mathrm{TiO}_{2}$ membrane by sintering the porous stainless steel matrix of $316 \mathrm{~L}$ with 60 mesh and 400 mesh after hanging slurry could also reflect the porous stainless steel matrix of 100 mesh and 200 mesh. Two stainless steel substrates with different powder particles of 60 and 400 mesh were selected for sintering at 1170,1200 and $1230^{\circ} \mathrm{C}$ different sintering temperatures to prepare $\mathrm{TiO}_{2}$ membrane after slurry sintering process. The sintering temperature of powder after slurry grouting was selected to be $650^{\circ} \mathrm{C}$, and the influence of other sintering temperatures on $\mathrm{TiO}_{2}$ membrane will be discussed later. As shown in Fig. $8 a$, $b$, this is the cross-sectional micrograph of the porous matrix prepared by sintering at $1170^{\circ} \mathrm{C}$ and hanging slurry after sintering at $650^{\circ} \mathrm{C}$. It can be clearly observed from Fig. 8a that $\mathrm{TiO}_{2}$ powder particles are filled in the pores of the porous matrix, and the morphology of $\mathrm{TiO}_{2}$ membrane is obviously different from that of the matrix. The flatness of $\mathrm{TiO}_{2}$ membrane is relatively poor, and the binding effect between $\mathrm{TiO}_{2}$ powder particles and the matrix is good. It can be observed from Fig. 8b) that $\mathrm{TiO}_{2}$ powder particles are distributed in the matrix pores and are well combined with the matrix without obvious gaps. However, $\mathrm{TiO}_{2}$ membrane is significantly lower than the plane where the matrix hole is located, the reason is that the matrix hole size of the 400 mesh $316 \mathrm{~L}$ stainless steel powder is small. The adsorption capacity of the cavity to $\mathrm{TiO}_{2}$ powder 

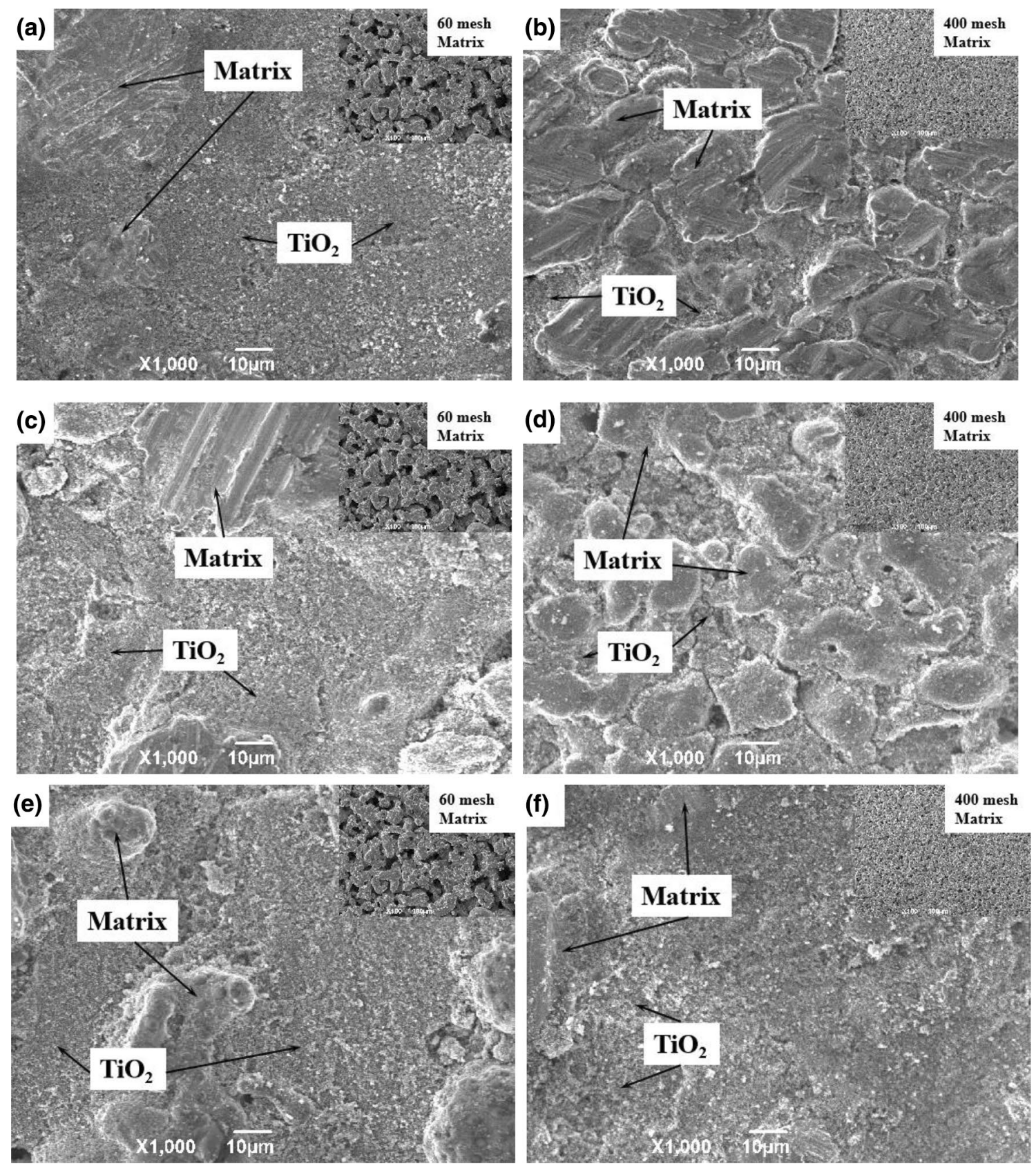

Fig. 8 SEM morphology of porous composite materials (316 L-TiO membrane) prepared by hanging slurry process at sintering temperature of $650^{\circ} \mathrm{C}$ according to $316 \mathrm{~L}$ stainless steel powder of dif-

ferent particles size at defferent sintering temperature of $1170{ }^{\circ} \mathrm{C}$ : (a) 60 mesh; (b) 400 mesh; $1200{ }^{\circ} \mathrm{C}:$ (c) 60 mesh; (d) 400 mesh; $1230^{\circ} \mathrm{C}$ : (e) 60 mesh; (f) 400 mesh

particles is relatively small. As a result, the amount of $\mathrm{TiO}_{2}$ particles aggregated in the pores is relatively small, and $\mathrm{TiO}_{2}$ powder particles formed by the combination between powder particles in the subsequent sintering process. As the binding between $\mathrm{TiO}_{2}$ particles is inward, the $\mathrm{TiO}_{2}$ particles are relatively lower than the pore plane of the matrix. By observing Fig. $8 \mathrm{a}, \mathrm{b}, \mathrm{TiO}_{2}$ membrane can be prepared by sintering at $650{ }^{\circ} \mathrm{C}$, and the combination between the film layer and the matrix is good. The porous matrix prepared

by 100 and 200 mesh powder shall be sintered to prepare the functionally gradient composite porous materials between the conditions shown in Fig. 8a, b. Figure 8c, $d$ show the micrographs of $\mathrm{TiO}_{2}$ membrane prepared by sintering $316 \mathrm{~L}$ stainless steel matrix at $1200^{\circ} \mathrm{C}$. It can be observed from Fig. $8 \mathrm{c}$ that the matrix and $\mathrm{TiO}_{2}$ membrane are clearly visible and they are well combined. However, some small cracks appeared inside the $\mathrm{TiO}_{2}$ ceramic layer, and these small cracks did not lead to $\mathrm{TiO}_{2}$ membrane 
cracking. The reason for this phenomenon is that the strength of $\mathrm{TiO}_{2}$ membrane is somewhat low during the sample preparation process, which results in partial peeling off. After further magnification, it looks like a crack, but this does not reflect the binding strength of $\mathrm{TiO}_{2}$ ceramic layer and matrix, nor does it affect the filtration accuracy and transmittance of $\mathrm{TiO}_{2}$ ceramic membrane. It can be clearly observed from Fig. 8d that $\mathrm{TiO}_{2}$ powder particles are filled in the pores of the matrix. $\mathrm{TiO}_{2}$ membrane was formed through sintering, but due to the small hole size of the matrix, the area of $\mathrm{TiO}_{2}$ membrane formed was small and discontinuous. It can be observed from the figure that cracks appear at the connection between $\mathrm{TiO}_{2}$ membrane and matrix, and pits appear in $\mathrm{TiO}_{2}$ membrane. The reason is that the strength of the film layer is relatively low, during the sample preparation process, $\mathrm{TiO}_{2}$ membrane falls off at a certain thickness, and then presents the morphology as shown in the figure. The reason for the film to fall off to a certain extent is that during the slurry hanging process, the friction coefficient of the hole and hole wall increases due to the high sintering temperature of the matrix. Furthermore, the absorption capacity of $\mathrm{TiO}_{2}$ powder particles in the cavity becomes larger, and a certain amount of $\mathrm{TiO}_{2}$ powder particles are gathered in the interior of the cavity and the entrance. In the subsequent sintering process, the particles inside the hole are well combined with the matrix and $\mathrm{TiO}_{2}$ membrane is formed. Due to the lack of interaction between $\mathrm{TiO}_{2}$ powder particles and pore wall at the mouth of the cave, the film layer strength of this part is low and easy to fall off with the matrix. Then during the sample making process, the appearance as shown in the picture appeared. However, the cracks did not affect the bonding strength between $\mathrm{TiO}_{2}$ ceramic layer and the substrate, nor did they affect the filtration accuracy and transmittance of the membrane layer. It can be predicted that the conditions of preparing $\mathrm{TiO}_{2}$ powder particles after the substrate prepared by the 100 and 200 mesh powder particles of the porous matrix prepared by $1200^{\circ} \mathrm{C}$ sintering are similar, between what shows in Fig. $8 c$, d. Figure 8 e is the microstructure diagram of $\mathrm{TiO}_{2}$ membrane prepared by sloughing porous matrix at the temperature of $1230^{\circ} \mathrm{C}$ and at sintering temperature of $650^{\circ} \mathrm{C}$. From this diagram, it can be clearly observed that the membrane prepared by $\mathrm{TiO}_{2}$ particles through sintering has a good combination with the matrix. Moreover, $\mathrm{TiO}_{2}$ membrane has good evenness, and it also can be seen from the figure that $\mathrm{TiO}_{2}$ membrane is lower than the plane of the matrix hole. The reason is that the matrix has a high temperature in the preparation and sintering process, which increases the friction coefficient of the pore wall and the adsorption capacity of $\mathrm{TiO}_{2}$ powder particles in the hanging slurry process increases, resulting in a large number of $\mathrm{TiO}_{2}$ powder particles entering the pores. In subsequent sintering, $\mathrm{TiO}_{2}$ powder particles were more concentrated in the interior of the hole and far away from the orifice of the hole, thus highlighting the pore wall of the matrix.

Figure $8 \mathrm{f}$ is the microstructure diagram of $\mathrm{TiO}_{2}$ membrane prepared by the porous matrix of 400 mesh powder particles at $1230^{\circ} \mathrm{C}$ sintering temperature and $650^{\circ} \mathrm{C}$ sintering after sloughing. It can be seen from the figure that $\mathrm{TiO}_{2}$ membrane has a good flatness and covers the porous substrate. The reason is that the diameter of the matrix prepared by 400 mesh stainless steel powder is small. However, due to the high sintering temperature and the increased friction coefficient of the matrix pore wall, there are relatively more specific $\mathrm{TiO}_{2}$ particles in the hole during the hanging slurry process. After sintering, a layer of $\mathrm{TiO}_{2}$ membrane will be formed at the orifice of the matrix hole. Due to the high strength of the film layer, it did not fall off during the sample preparation process, presenting the morphology as shown in the figure. The cause of the high strength of the coatings is roughly matrix substrate in the process of preparation of high sintering temperature hole wall friction coefficient is big, and holes of $\mathrm{TiO}_{2}$ powder particles adsorption force become larger, resulting in mouth hole diameter, the relatively increased number of $\mathrm{TiO}_{2}$ particles, making $\mathrm{TiO}_{2}$ after subsequent sintering ceramic membrane layer on the mouth of the hole diameter of the matrix bonding strength increased.

By comparing the six pictures in Fig. 8 , it can be seen that it is feasible to sintered ceramic porous composites at $650^{\circ} \mathrm{C}$ after hanging the porous matrix. The ceramic layer is well combined with the porous matrix. However, the pore size of the porous matrix and the friction coefficient of the pore wall affect the thickness and strength of $\mathrm{TiO}_{2}$ membrane.

The microstructure and microstructure of porous ceramic materials prepared by sintering at different temperatures after hanging different $316 \mathrm{~L}$ stainless steel matrix are shown in Fig. 9. It can be clearly seen from Fig. 9a that $\mathrm{TiO}_{2}$ membrane is well combined with the porous matrix after sintering at $700^{\circ} \mathrm{C}$ for the $316 \mathrm{~L}$ stainless steel matrix prepared by 100 mesh powder particles. The membrane is slightly lower than the hole plane of the matrix, but the membrane has good leveling property. It can be observed from Fig. $9 \mathrm{~b}$ that the porous matrix is sintered and prepared by 200 mesh particles, and the ceramic composite porous material is prepared by resintering after slaking. The membrane almost covers the plane of the matrix hole, and the matrix rarely highlights the membrane. This indicates that the porous matrix prepared by $1200^{\circ} \mathrm{C}$ sintering is suitable for the sintering of $\mathrm{TiO}_{2}$ powder particles at a sintering temperature of $700^{\circ} \mathrm{C}$ after slurry laying, and the integrity of metal-ceramic composite porous material is good. The microstructure of the porous ceramic composites prepared by sintering 

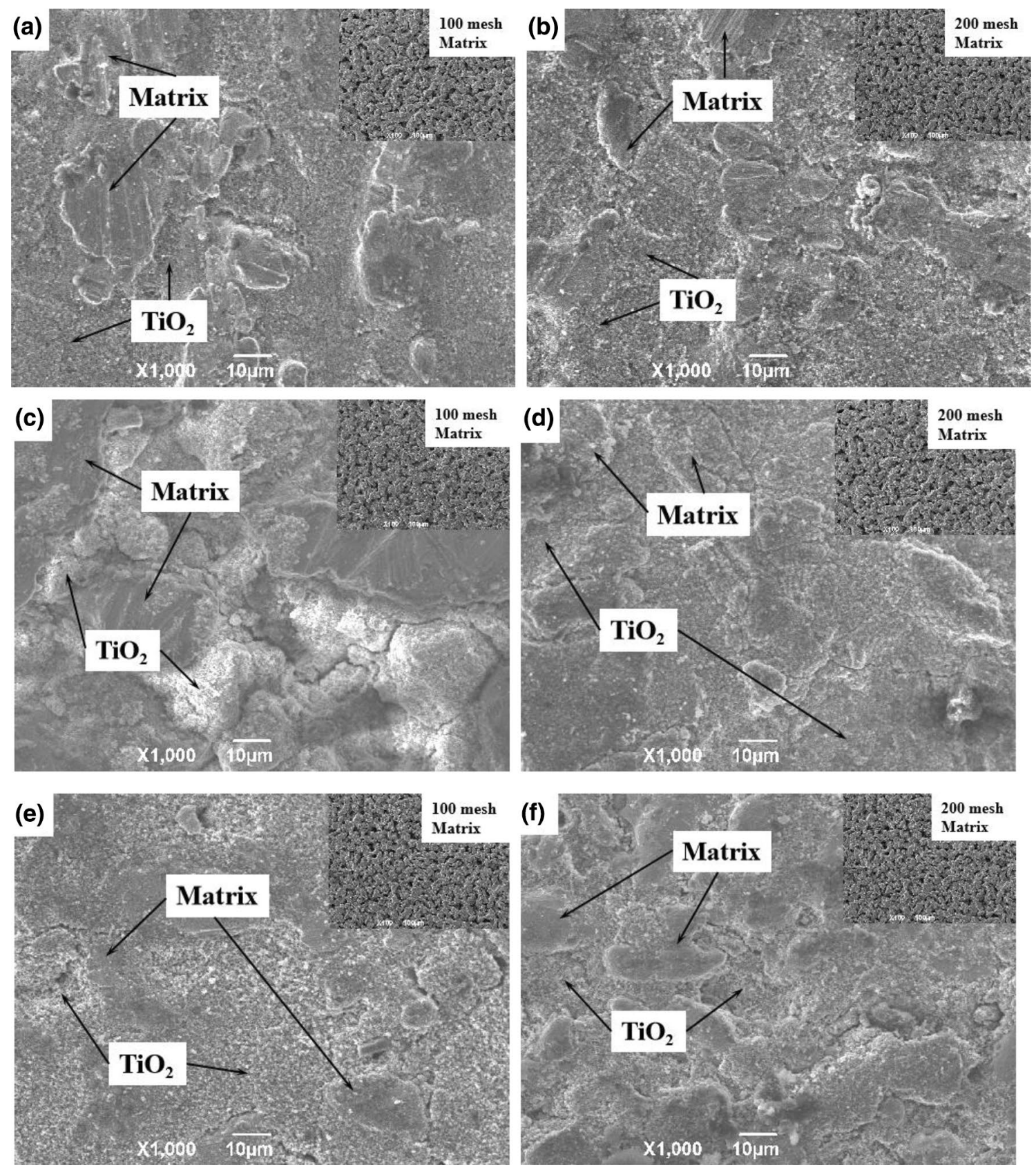

Fig. 9 Transverse SEM morphology of porous composite materials (316 $\mathrm{L}-\mathrm{TiO}_{2}$ membrane) prepared by hanging slurry process at different sintering temperature of $700,750,800^{\circ} \mathrm{C}$ according to $316 \mathrm{~L}$

at $750{ }^{\circ} \mathrm{C}$ after hanging slurry process the same porous matrix is shown in Fig. 9c, d. It can be clearly observed from Fig. $9 \mathrm{c}$ that $\mathrm{TiO}_{2}$ membrane is well combined with porous matrix. $\mathrm{TiO}_{2}$ particles are filled in the pores of the porous matrix, and a certain amount of $\mathrm{TiO}_{2}$ powder particles are gathered inside the pores of the porous matrix and at the surface of the pores. However, the internal bonding strength of $\mathrm{TiO}_{2}$ ceramic layer is poor, and some local pits appear. This indicates that some of the film layers have stainless steel powder of different particles size at defferent sintering temperature of $1170^{\circ} \mathrm{C}$ : (a) 100 mesh; (b) 200 mesh; $1200^{\circ} \mathrm{C}$ : (c) 100 mesh; (d) 200 mesh; $1230^{\circ} \mathrm{C}:$ (e) 100 mesh; (f) 200 mesh

fallen off. At the same time, some cracks were found in $\mathrm{TiO}_{2}$ membrane after its internal peeling off. The reason is that the sintering temperature is too high and the cooling rate is fast. It can be clearly observed from Fig. $9 d$ that $\mathrm{TiO}_{2}$ membrane has a good combination with the matrix, and the membrane is relatively thick, almost covering the hole plane of the porous matrix. At the same time, some cracks were also found in the ceramic layer of $\mathrm{TiO}_{2}$. This indicates that the strength of $\mathrm{TiO}_{2}$ membrane along the 
direction of thickness is low, which makes the thicker $\mathrm{TiO}_{2}$ membrane fall off in some parts. The reason is that the sintering temperature is slightly higher and the overfiring phenomenon occurs, which leads to the reduction of the bonding strength. However, this does not affect the filtration accuracy and permeability of the ceramic membrane. The same porous matrix was put into the sintering procedure after hanging slurry process, and the sintering temperature was selected at $800^{\circ} \mathrm{C}$. The micro-structure of the prepared porous cermet composite is shown in Fig. 9e, f. It can be clearly observed from Fig. 9 e that $\mathrm{TiO}_{2}$ membrane is well combined with the matrix and the ceramic layer covers the plane of the matrix hole, which indicates that $\mathrm{TiO}_{2}$ membrane thickness is relatively large. As we know that the matrix pores have a strong adsorption of $\mathrm{TiO}_{2}$ powder particles, and a large number of $\mathrm{TiO}_{2}$ powder particles are gathered and formed a relatively thick $\mathrm{TiO}_{2}$ membrane through sintering. However, the lightness of the ceramic layer itself still needs to be improved. It can be observed from Fig. 9e that some local cracks exist, but the length and depth of the crack are not great, this indicates that the binding strength is still very good, which may lead to the generation of microcracks in the sample preparation process. Figure $9 f$ is a functionally gradient composite porous material prepared by sintering after slurry hanging on a 200 mesh matrix. It can be seen from the figure that $\mathrm{TiO}_{2}$ ceramic layer covers the pore plane of the porous matrix. $\mathrm{TiO}_{2}$ membrane is well combined with porous matrix, and some parts of ceramic layer are detached, this means that the internal bonding strength of the ceramic layer is not ideal. This phenomenon shows us that although a certain amount of $\mathrm{TiO}_{2}$ powder particles are gathered in the matrix holes, the bonding strength between powder particles is not very good, and some parts of $\mathrm{TiO}_{2}$ membrane fall off during the sample preparation. By comparing these pictures in Fig. 9, it was found that $\mathrm{TiO}_{2}$ membrane had relatively good integrity at the sintering temperature of $700^{\circ} \mathrm{C}$, and $\mathrm{TiO}_{2}$ membrane had a good combination with porous matrix. The results show that the sintering temperature of $700^{\circ} \mathrm{C}$ is suitable for the preparation of porous ceramic matrix of $316 \mathrm{~L}$ stainless steel through sintering. The integrity of $\mathrm{TiO}_{2}$ membrane is poor at the sintering temperature of $750{ }^{\circ} \mathrm{C}$. It may be that the over-firing caused by slightly higher sintering temperature reduces the strength of $\mathrm{TiO}_{2}$ membrane and leads to the phenomenon of peeling off. It indicates that the sintering temperature of $750{ }^{\circ} \mathrm{C}$ is not suitable for the preparation of ceram porous composites by sintering $316 \mathrm{~L}$ stainless steel matrix after hanging slurry process. Then $\mathrm{TiO}_{2}$ ceramic layer at the sintering temperature of $800^{\circ} \mathrm{C}$ is between the twos. The integrity of this film layer is slightly worse than that of $\mathrm{TiO}_{2}$ membrane at $700^{\circ} \mathrm{C}$, but significantly better than that of $\mathrm{TiO}_{2}$ membrane at $750^{\circ} \mathrm{C}$.
The reason for this is that the internal phase composition of $\mathrm{TiO}_{2}$ ceramic layer changes, and there is a phase transition from the striated mineral structure to rutile structure between 750 and $800{ }^{\circ} \mathrm{C}$, which affects the strength of $\mathrm{TiO}_{2}$ ceramic layer itself. As the transformation of the two phases is not very thorough, a small amount of phases with striated mineral structure will be retained in $\mathrm{TiO}_{2}$ membrane. Moreover, due to the high sintering temperature, $\mathrm{TiO}_{2}$ membrane also has a small amount of shedding. However, the overall quality was significantly better than that of $\mathrm{TiO}_{2}$ ceramic layer prepared by sintering at $750^{\circ} \mathrm{C}$. This indicates that in the absence of phase transition, too high sintering temperature is not conducive to improving the strength of $\mathrm{TiO}_{2}$ membrane, and too high sintering temperature will lead to phase transformation inside $\mathrm{TiO}_{2}$ membrane, which can appropriately improve the integrity of the film.

By comparing Figs. 8 and 9, it can be seen that $\mathrm{TiO}_{2}$ ceramic membrane prepared by sintering at $650^{\circ} \mathrm{C}$ with $316 \mathrm{~L}$ porous stainless steel matrix prepared at $1230^{\circ} \mathrm{C}$ has the best quality. Furthermore, the quality of porous metalceramic composites prepared by this process is the best at micro-structure according to the observation and analysis.

\subsection{Permeability and max pore of the functionally gradient composite porous materials}

After sloughing the porous matrix of $316 \mathrm{~L}$ stainless steel prepared at $1230{ }^{\circ} \mathrm{C}$ sintering temperature, $\mathrm{TiO}_{2}$ membrane was sintered at $650^{\circ} \mathrm{C}$ to prepare the porous ceramic composite formed with the matrix, and its morphology was observed along the thickness direction, as shown in Fig. 10. Figure 10a is the micro structure diagram of 60 mesh $316 \mathrm{~L}$ stainless steel matrix prepared by sintering after hanging slurry process, and it can be clearly seen from the figure that $\mathrm{TiO}_{2}$ particles are filled in the pores of the porous matrix and reach a certain thickness which determines the thickness of $\mathrm{TiO}_{2}$ membrane. In addition, since the size of $\mathrm{TiO}_{2}$ powder particles is consistent, the thickness of the membrane depends on the number of $\mathrm{TiO}_{2}$ powder particles accumulated during sintering. However, the aggregation amount of $\mathrm{TiO}_{2}$ particles depends on the adsorption force of the porous matrix, while the adsorption force of the porous matrix depends on the size of the pore diameter of the porous matrix and the friction coefficient of the pore wall. The pore wall friction coefficient of the porous matrix prepared by stainless steel powder at the sintering temperature of $1230^{\circ} \mathrm{C}$ is the largest, and the pore size is also the largest. Therefore, in the slurry hanging process, the pores of the matrix have relatively strong adsorption capacity, the amount of accumulated $\mathrm{TiO}_{2}$ powder particles is relatively large, and the thickness of $\mathrm{TiO}_{2}$ membrane obtained through sintering is also 

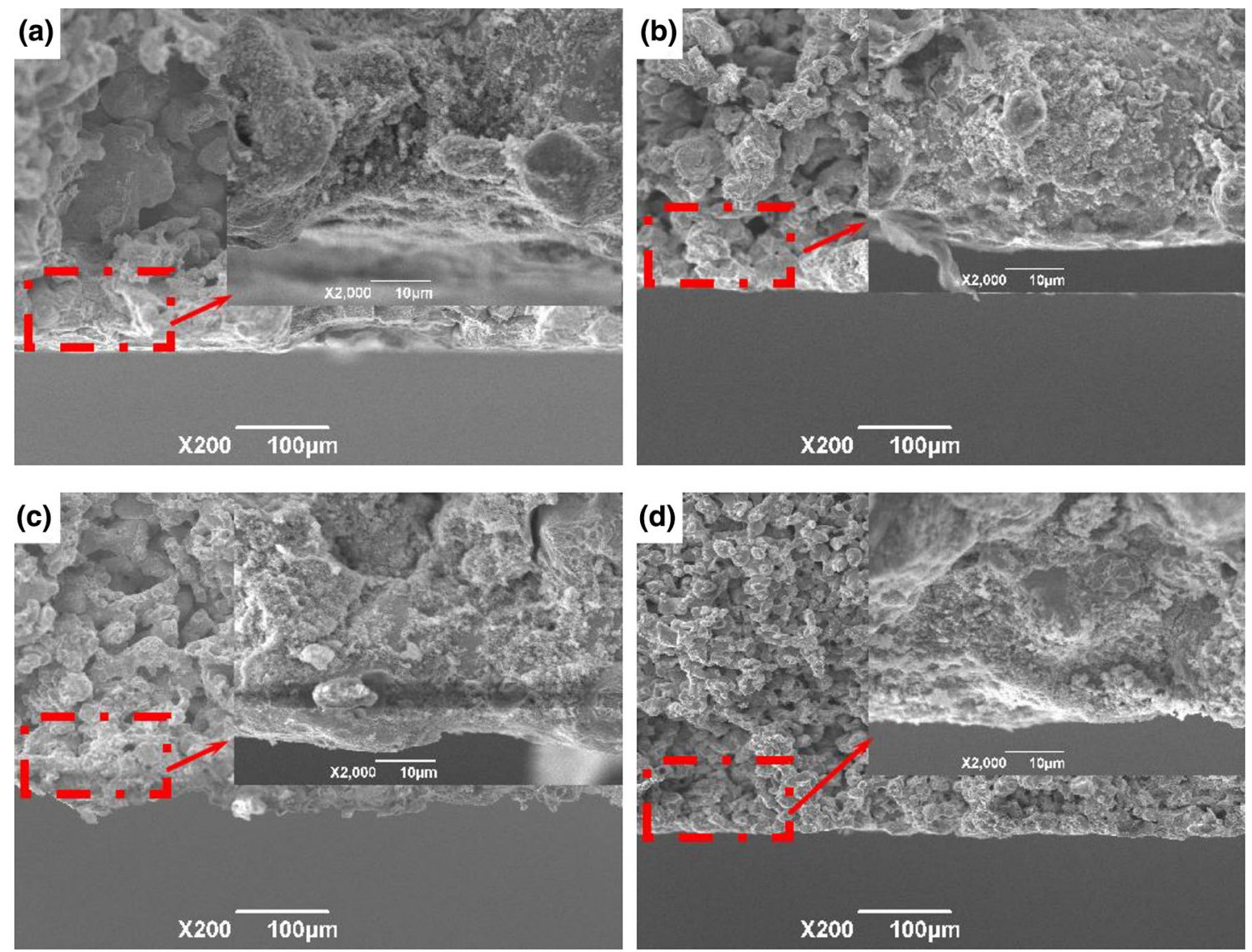

Fig. 10 Longitudinal SEM morphology of porous composite materials (316 ${\mathrm{L}-\mathrm{TiO}_{2}}_{2}$ membrane) prepared by hanging slurry process at sintering temperature of $650{ }^{\circ} \mathrm{C}$ according to $316 \mathrm{~L}$ stainless

steel powder of different particles size at sintering temperature of $1230^{\circ} \mathrm{C}$ : (a) 60 mesh; (b) 100 mesh; (c) 200 mesh; (d) 400 mesh

relatively maximum. At the same sintering temperature, the smaller the particle size of $316 \mathrm{~L}$ powder is, the smaller the pore diameter of the prepared porous matrix is, and the smaller the friction coefficient of the pore wall is. Therefore, the adsorption capacity of the porous matrix is relatively small in the slurry hanging process. The amount of $\mathrm{TiO}_{2}$ powder particles accumulated in the pores is relatively small, and the $\mathrm{TiO}_{2}$ membrane prepared by sintering is relatively thin.

From Fig. 10a, it can be clearly observed that $\mathrm{TiO}_{2}$ powder particles fill into the matrix holes and reach a certain thickness. The $\mathrm{TiO}_{2}$ membrane formed significantly improves the filtration accuracy of the original matrix. However, the three-connection structure in the matrix was not completely blocked, so the presence of the film significantly improved the filtration accuracy of the matrix without affecting the flux. Figure 10b shows the microstructure of porous ceramic composites prepared by sintering after hanging pulp on the basis of 100 mesh stainless steel powder particles. It can be observed from the figure that the thickness of $\mathrm{TiO}_{2}$ membrane prepared is smaller than

that shown in Fig. 10a. The reason is that the pore size of the porous matrix is small and the friction coefficient of the pore wall is small, so the adsorption force of the pore is relatively small. Therefore, the amount of $\mathrm{TiO}_{2}$ powder particles gathered near the pores is relatively small, which leads to the thinner $\mathrm{TiO}_{2}$ membrane. However, it can be clearly seen from the figure that $\mathrm{TiO}_{2}$ membrane has a good combination with the matrix and fills the holes in the matrix, which can significantly improve the filtration accuracy of the matrix. At the same time, the three-connection structure of the matrix was clearly visible, indicating that $\mathrm{TiO}_{2}$ ceramic membrane did not hinder the flux of the matrix. Figure 10c shows the micro structure of ceramic composite porous material prepared by 200 mesh $316 \mathrm{~L}$ stainless steel powder sintered matrix after slurry hanging and sintering. It can be clearly observed from the figure that $\mathrm{TiO}_{2}$ membrane is well combined with the matrix, and $\mathrm{TiO}_{2}$ powder particles are filled in the pores of the porous matrix. $\mathrm{TiO}_{2}$ membrane covers the surface of the matrix and reaches a certain thickness. The ceramic layer can improve the filtration accuracy of the substrate, but the 
three-connection structure inside the substrate ensures the flux of the substrate. The thickness of the membrane is directly related to the pore structure and morphology of the matrix. Due to the small size of the powder particles in the prepared matrix, the pore diameter of the matrix and the friction coefficient of the pore wall are relatively small, resulting in the small adsorption force of the pores in the matrix during the slurry hanging process. Therefore, the amount of $\mathrm{TiO}_{2}$ powder particles gathered in the pores is small, resulting in the thinner $\mathrm{TiO}_{2}$ membrane thickness. However, this does not affect the filtration accuracy of the membrane.

Figure $10 \mathrm{~d}$ shows the micro structure of the porous matrix prepared by 400 mesh $316 \mathrm{~L}$ stainless steel powder sintered and prepared by slurry sintering. It can be seen from the figure that the pore size of the porous matrix becomes smaller, leading to a significant decrease in the thickness of $\mathrm{TiO}_{2}$ membrane. However, $\mathrm{TiO}_{2}$ powder particles were filled in the holes, and $\mathrm{TiO}_{2}$ membrane formed a good combination with the matrix. The filtration accuracy of the matrix can be improved obviously, but the threeconnection structure of the matrix ensures the circulating flux.

By comparing the four figures in Fig. 10, it can be observed that the thickness of $\mathrm{TiO}_{2}$ membrane is directly related to the adsorption capacity of the substrate in the slurry hanging process. The adsorption capacity of the matrix is closely related to the pore size and the friction coefficient of the pore wall. Therefore, the larger the pore size of the matrix and the larger the particle size of the $316 \mathrm{~L}$ powder prepared by the matrix, the greater the thickness of $\mathrm{TiO}_{2}$ membrane prepared, and vice versa. However, the thickness of $\mathrm{TiO}_{2}$ ceramic layer has no relationship with its filtration accuracy. The direct factors affecting the filtration accuracy of $\mathrm{TiO}_{2}$ membrane are the size of $\mathrm{TiO}_{2}$ powder particles and sintering temperature of membrane. Because the size of $\mathrm{TiO}_{2}$ powder particles directly affects the binding gap, that is, the hole size of the film layer, and the sintering temperature of $\mathrm{TiO}_{2}$ membrane affects its porous structure, and the combined effect of the two influences the filtration accuracy of $\mathrm{TiO}_{2}$ membrane. The pore size of the porous matrix is significantly larger than that of the $\mathrm{TiO}_{2}$ membrane, so the matrix has no influence on the filtration accuracy, but only affects the flux.

Table 4 shows the permeability coefficient of all samples of functionally gradient composite porous materials prepared by slurry method. Since the temperature of preparing $316 \mathrm{~L}$ stainless steel porous matrix is three kinds and the powder particles of $316 \mathrm{~L}$ stainless steel are four kinds, there are 12 porous matrix of $316 \mathrm{~L}$ stainless steel. Each matrix was treated with slurry to prepare functionally gradient composite porous materials. Since there were four sintering temperatures of $\mathrm{TiO}_{2}$ membrane after hanging slurry process, a total of 48 kinds of samples were prepared for functionally gradient composite porous materials. Test the permeability of each sample, and the results are shown in Table 4 and Fig. 11. By analyzing the data in Table 4 and Fig. 11, it can be seen that the particle size of the prepared matrix, the sintering temperature of the powder and the sintering temperature after slurry all affect the change of the permeability coefficient of $316{\mathrm{~L}-\mathrm{TiO}_{2}}_{2}$ gradient composite porous material. The main reason for the influence of $316 \mathrm{~L}$ stainless steel matrix on the permeability of functionally gradient composite porous materials lies in its pore morphology and pore size, which directly affects the thickness of ceramic film layer and then the permeability of functionally gradient composite porous materials. $\mathrm{TiO}_{2}$ ceramic film has little influence on the pore size of the film due to its small particle details and small sintering temperature range. The filtration pass rate of $\mathrm{TiO}_{2}$ membrane is mainly affected by the thickness of the film.

The porous matrix prepared by 400 mesh $316 \mathrm{~L}$ stainless steel powder under the sintering condition of $1230^{\circ} \mathrm{C}$ can be seen in Table 4 and Fig. 11. The functionally gradient composite porous materials prepared by sintering at $650^{\circ} \mathrm{C}$ after hanging pulp has the highest permeability. The reason is that the pore size of the matrix is the smallest, the amount of $\mathrm{TiO}_{2}$ particles aggregated in the pores of the matrix is small, and the film thickness formed in the subsequent sintering process is the thinnest. Due to sintering in the range of $650-800^{\circ} \mathrm{C}$, phase composition of $\mathrm{TiO}_{2}$ ceramic film layer will be different. The structure of $650-750^{\circ} \mathrm{C}$ is more of a
Table 4 Permeability coefficient of the functionally gradient composite porous materials preparation with $316 \mathrm{~L}$ stainless steel matrix by hanging slurry process at different sintering temperature $\left(\mathrm{m}^{3} \mathrm{~h}^{-1} \mathrm{~m}^{-2}\right)$

\begin{tabular}{|c|c|c|c|c|c|c|c|c|c|c|c|c|}
\hline \multirow{3}{*}{$\begin{array}{l}\text { Sintering temperature } \\
\text { of } \mathrm{TiO}_{2} \text { membrane }\end{array}$} & \multicolumn{4}{|c|}{$1170^{\circ} \mathrm{C}$} & \multicolumn{4}{|c|}{$1200^{\circ} \mathrm{C}$} & \multicolumn{4}{|c|}{$1230^{\circ} \mathrm{C}$} \\
\hline & \multicolumn{12}{|c|}{ Particle size of $316 \mathrm{~L}$ stainless steel matrix powder (mesh) } \\
\hline & 60 & 100 & 200 & 400 & 60 & 100 & 200 & 400 & 60 & 100 & 200 & 400 \\
\hline $650^{\circ} \mathrm{C}$ & 18 & 20 & 21 & 22 & 19 & 21 & 22 & 23 & 19 & 22 & 23 & 24 \\
\hline $700{ }^{\circ} \mathrm{C}$ & 17 & 19 & 20 & 21 & 18 & 21 & 22 & 23 & 17 & 20 & 21 & 22 \\
\hline $750^{\circ} \mathrm{C}$ & 17 & 19 & 20 & 21 & 18 & 21 & 22 & 23 & 17 & 20 & 21 & 22 \\
\hline $800^{\circ} \mathrm{C}$ & 16 & 18 & 19 & 20 & 17 & 20 & 21 & 22 & 16 & 19 & 20 & 21 \\
\hline
\end{tabular}



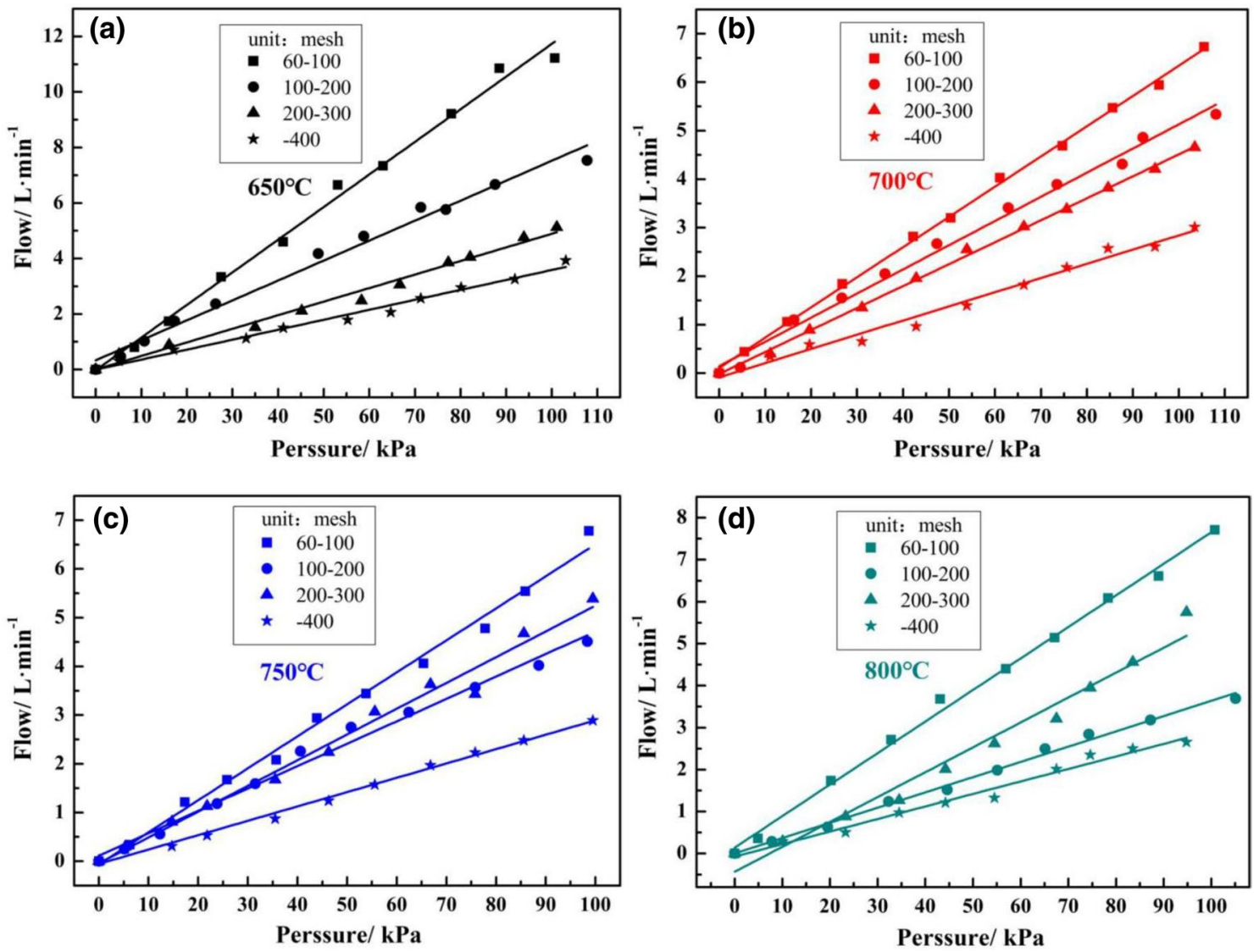

Fig. 11 Permeability of functionally gradient composite porous materials ( $316{\mathrm{~L}-\mathrm{TiO}_{2}}_{2}$ membrane) prepared by hanging slurry process at different sintering temperature of $650,700,750$, and $800^{\circ} \mathrm{C}$

Anatase structure, and the structure of $800{ }^{\circ} \mathrm{C}$ is more of a Rutile structure. But their different structures have little influence on the permeability of the membrane. This indicates that the transmittance of $\mathrm{TiO}_{2}$ ceramic layer is mainly determined by the thickness of the film layer on the premise of ensuring the filtration accuracy. The pore size of $\mathrm{TiO}_{2}$ ceramic layer is much smaller than that of the substrate. Therefore, the permeability change of cermets composite porous materials has little relationship with the pore size of the matrix, which is mainly determined by the permeability of $\mathrm{TiO}_{2}$ ceramic film layer. However, the pore structure and pore size of the matrix affect the maximum flux of the composite.

\section{Conclusions}

1. $316 \mathrm{~L}$ stainless steel porous materials can be prepared at sintering temperature of 1170,1200 and $1230^{\circ} \mathrm{C}$ for different powder particle sizes of $60,100,200$ and 400 mesh, and its pore size has little relation with sintering temperature and close relation with powder particle size.

2. The functionally gradient composite porous materials can be prepared by $316 \mathrm{~L}$ stainless steel porous matrix with different pore sizes after hanging slurry process at sintering temperature of $650-800^{\circ} \mathrm{C}$.

3. $\mathrm{TiO}_{2}$ membrane thickness of the functionally gradient composite porous materials is closely related to the powder particle size and sintering temperature of the $316 \mathrm{~L}$ matrix.

4. The functionally gradient composite porous materials prepared on the basis of the matrix of $316 \mathrm{~L}$ stainless steel powder prepared at 400 mesh have the maximum permeability of $24 \mathrm{~m}^{3} \mathrm{~h}^{-1} \mathrm{~m}^{-2}$.

5. The permeability of $316 \mathrm{~L}$ stainless steel matrix can be significantly affected by combining $\mathrm{TiO}_{2}$ membrane. For different porous matrix, the permeability can be decreased by $65.7-96.3 \%$. 
Acknowledgements This work was financially supported by the National Natural Science Foundation of China (Grant No. 51704239), the Open Foundation of Key Laboratory of Material Electromagnetic Process Research Ministry of Education Northeastern University (Project No. NEU-EPM-013), the Innovation Team Foundation by Xi'an Shiyou University (Project No.2019QNKYCXTD12) and Youth Science and Technology Innovation Project of Xi'an Shiyou University (Project No.2016BS21).

\section{Compliance with ethical standards}

Conflict of interest The authors declare that they do not have any competing financial interests or personal relationships that could have influenced the work reported in this paper.

\section{References}

1. Brothers AH, Dunand DC (2008) Mechanical properties of a density-graded replicated aluminum foam. Mater Sci Eng A 489(1-2):439

2. Shi M, Li Z, Yuan Y et al (2015) In situ oxidized magnetite membranes from $316 \mathrm{~L}$ porous stainless steel via a two-stage sintering process for hexavalent chromium $[\mathrm{Cr}(\mathrm{VI})]$ removal from aqueous solutions. Chem Eng J 265:84-92

3. Gregorutti RW, Elsner Cl, Garrido L et al (2015) Corrosion in 316L porous prostheses obtained by gelcasting. Procedia Mater Sci 9:279-284

4. Garcia-Lobato MA, Mtz-Enriquez Al, Garcia CR et al (2019) Corrosion resistance and in vitro bioactivity of dense and porous titania coatings deposited on 316L SS by spraying method. Appl Surf Sci 484:975-980

5. Huiping T, Qing Z, Zhengping X et al (2007) The relation between the maximum bubble diameter and filtration accuracy of metal porous materials. Rare Metal Mater Eng 36(s3):559-561

6. Zhengping $X$, Huiping $T$ (2008) Sintered me-tallic porous material. Metallurgical Industry Press, Beijing

7. Zhao L (2003) Berichte des Forschungszentrums, Jülich

8. Li Z, Qiu N, Yang G (2009) Effects of synthesis parameters on the microstructure and phase structure of porous $316 \mathrm{~L}$ stainless steel supported $\mathrm{TiO}_{2}$ membranes. J Membr Sci 326(2):533-538

9. Wen L, Wanpei H, Qian L et al (2020) Antibacterial properties of $\mathrm{Ag} / \mathrm{TiO}_{2} / \mathrm{PDA}$ nanofilm on anodized $316 \mathrm{~L}$ stainless steel substrate under illumination by a normal flashlight[J]. J Mater Sci 2020(55):9538-9550

10. Mirzaei M, Paydar MH (2018) Fabrication and characterization of core-shell density -graded $316 \mathrm{~L}$ stainless steel porous structure. $J$ Mater Eng Perform 28(1):221-230

11. Wahab NA, Ahmad IN, Omar NF et al (2018) Processing of porous $316 \mathrm{~L}$ stainless steel by replacing metal powder with saccharose. International Journal of Engineering \& Technology 7:232-236

12. Falkowska A, Seweryn A (2015) Fatigue of sintered porous materials based on $316 \mathrm{~L}$ stainless steel under uniaxial loading. Mater Sci 51(2):200-207

13. Kim WJ, Nguyen HH, Kim HY et al (2017) Sintering and microstructures of SUS 316L powder produced by 3D printing process. Arch Metall Mater 62(2):1215-1218

14. Sidane $\mathrm{D}$, Khireddine $\mathrm{H}, \mathrm{Bir} F$ et al (2017) Hydroxyapatite- $\mathrm{TiO}_{2}$ $\mathrm{SiO}_{2}$-coated $316 \mathrm{~L}$ stainless steel for biomedical application. Metall Mater Trans A 48(7):3570-3582

15. Huan Z, Fratila-Apachitei LE, Apachitei I et al (2012) Characterization of porous $\mathrm{TiO}_{2}$ surfaces formed on $316 \mathrm{~L}$ stainless steel by plasma electrolytic oxidation for stent applications. $J$ Funct Biomater 3(2):349-360

16. Ismail A, Rahman MNA, Sadikin A et al (2018) The effect of different urea composition on production of porous stainless steel type $316 \mathrm{~L}$ through powder metallurgy technique. Int J Curr Resear Sci Eng Technol 1(S1):32-36

17. Fogliatto $A A B$, Ahrens $C H$, Wendhausen PAP et al (2020) Correlation between porosity and permeability of stainless steel filters with gradient porosity produced by SLS/SLM. Rapid Prototyp J 26(1):73-81

18. Wang L, Xie J, Bin X (2016) Advances in porous ceramic membranes. Powder Metall Indust 26(03):69-77

19. Li RD, Liu JH, Shi YS et al (2010) 316L stainless steel with gradient porosity fabricated by selective laser melting. J Mater Eng Perform 19(5):666

20. Song T, Yan M, Qian M (2018) The enabling role of dealloying in the creation of specific hierarchical porous metal structures-A review. Corros Sci 134:78-98

21. Wang Q, Huiping T, Yang B (2016) Research on the continuously graded porous metal materials. Prog Mater China 35(02):136-140

22. Kang $X$, Wang $Q$, Fan $S$ et al (2018) The influence of grain size and height deviation on XRD. Guangzhou Chem 43(05):1-10

23. Zhu M, Zhu L, Wang J et al (2017) Adsorption of Cd(II) and $\mathrm{Pb}$ (II) by in situ oxidized Fe3O4 membrane grafted on 316L porous stainless steel filter tube and its potential application for drinking water treatment. J Environ Manag 196:127-136

24. Wang Y, Liu Z, Zhang X et al (2019) Influences of oxygen on corrosion characteristics of $\mathrm{TiO}_{2} / 316 \mathrm{~L}$ stainless steel in supercritical water. Int J Hydrog Energy 44(11):5099-5107

25. Mozammel M, Khajeh M, Ilkhechi NN (2018) Effect of surface roughness of $316 \mathrm{~L}$ stainless steel substrate on the morphological and super-hydrophobic property of $\mathrm{TiO}_{2}$ thin films coatings. Silicon 10(6):2603-2607

26. Bu A, Ji G, Liu Q et al (2018) Effect of different zirconium contents on the corrosion resistance of $\mathrm{ZrO}_{2}-\mathrm{TiO}_{2}$ film-coated stainless steel. J Mater Eng Perform 27(10):5321-5328

27. Adán C, Marugán J, Mesones S et al (2017) Bacterial inactivation and degradation of organic molecules by titanium dioxide supported on porous stainless steel photocatalytic membranes. Chem Eng J 318:29-38

28. Wang $M$, Zhong Q-f, Xu Z-L et al (2016) Modification of porous stainless steel hollow fibers by adding $\mathrm{TiO}_{2}, \mathrm{ZrO}_{2}$ and $\mathrm{SiO}_{2}$ nano-particles. J Porous Mater 23(3):773-782

29. Balamurugan A, Kannan S, Rajeswari S (2005) Evaluation of $\mathrm{TiO} 2$ coatings obtained using the sol-gel technique on surgical grade type $316 \mathrm{~L}$ stainless steel in simulated body fluid. Mater Lett 59(24/25):3138-3143

30. Shin DY, Kim KN, Han SM (2005) Sol-gel derived TiO2 coating for chemical protection of stainless steel. Mater Sci Forum 486:5-8

31. Yu XG, Zuo Y, Ma HW, Zhao HF, Luo WW, Bi W et al (2007) Study on the macro-residual stress of 304 stainless steel coated with $\mathrm{TiO} 2-\mathrm{SiO} 2$ thin films by sol-gel process. Key Eng Mater 280-283:815-818

32. Barati N, Sani MAF, Ghasemi H, Sadeghian Z, Mirhoseini SMM (2009) Preparation of uniform TiO2 nanostructure film on $316 \mathrm{~L}$ stainless steel by sol-gel dip coating. Appl Surf Sci 255(20):8328-8333

33. Li J, Lin CJ, Lai YK, Du RG (2009) Photogenerated cathodic protection of flower-like, nanostructured, N-doped TiO2 film on stainless steel. Surf Coat Technol 205(2):557-564

34. Mechiakh R, Sedrine NB, Naceur JB, Chtourou R (2011) Elaboration and characterization of nanocrystalline $\mathrm{TiO} 2$ thin films prepared by sol-gel dip-coating. Surf Coat Technol 206(2-3):243-249 
35. Cheraghi H, Shahmiri M, Sadeghian Z (2012) Corrosion behavior of TiO2-NiO nanocomposite thin films on AISI 316L stainless steel prepared by sol-gel method. Thin Solid Films 522(none):289-296

36. Fu T, Wen CS, Lu J, Zhou YM, Ma SG, Dong BH et al (2012) Sol-gel derived $\mathrm{TiO} 2$ coating on plasma nitrided $316 \mathrm{~L}$ stainless steel. Vacuum. 86(9):1402-1407

37. Xie D, Wan G, Maitz MF, Sun H, Huang N (2013) Deformation and corrosion behaviors of $\mathrm{TiO} 2$ film deposited $316 \mathrm{~L}$ stainless steel by plasma immersion ion implantation and deposition. Surf Coat Technol 214(none):117-123

Publisher's Note Springer Nature remains neutral with regard to jurisdictional claims in published maps and institutional affiliations. 